\title{
Efficient Treatment of Lead-containing Wastewater Using Bagasse Biochar Modified via Hydroxylapatite
}

\author{
Qing Zhang, Lin Lu, Meina Liang,* Dunqiu Wang, Daolin Huang, and Yinian Zhu
}

\begin{abstract}
A hydroxylapatite bagasse biochar composite was prepared via the hydrothermal chemical precipitation method with bagasse as the primary raw material. The adsorption capacity of hydroxylapatite bagasse biochar composite for $\mathrm{Pb}$ (II) was determined using a series of batch adsorption experiments. The results showed that the point of zero charge value was near neutral $\mathrm{pH}$, and the optimal $\mathrm{pH}$ ranged from 4.0 to 7.0. Langmuir isotherms were suitable for fitting the isothermal adsorption process of $\mathrm{Pb}$ (II) by the hydroxylapatite bagasse biochar composite. The maximum adsorption capacity of hydroxylapatite bagasse biochar composite in terms of $\mathrm{Pb}$ (II) was $210 \mathrm{mg} \cdot \mathrm{g}^{-1}$ at $25^{\circ} \mathrm{C}$. Fourier transform infrared spectrometry analysis indicated that oxygen-containing functional groups were abundant on the external and internal surfaces of the composite sample, which provided numerous chemical sorption sites and resulted in an increase in the adsorption capacity of the composite sample. The $\mathrm{Pb}$ (II) removal mechanism of the hydroxylapatite bagasse biochar composite primarily utilized surface diffusion, electrostatic attraction, surface complexation, ion exchange, and a dissolving-coprecipitation reaction. The composite sample was suitable for the treatment of leadcontaminated water (containing zinc, arsenic, cadmium, etc.), which was a promising environmentally friendly material.
\end{abstract}

DOI: 10.15376/biores.17.1.1205-1231

Keywords: Hydroxylapatite; Bagasse biochar; Lead; Adsorption

Contact information: School of Environmental Science and Engineering, Guilin University of Technology, Guilin 541004 P.R. China; *Corresponding author: liangmeinaa@163.com

\section{INTRODUCTION}

Many industrial activities and manufacturing products, e.g., batteries, alloys, pigments, paints, smelting, mining, ceramics, and power generation, result in the introduction of $\mathrm{Pb}$ (II) to the environment (Meski et al. 2010). $\mathrm{Pb}$ (II) causes kidney and brain damage, a loss of learning ability in children, increased blood pressure, and a disruption in hemoglobin formation (Argun et al. 2007). Conventional lead wastewater treatment methods, e.g., chemical precipitation, ion-exchange, reverse osmosis, and electrochemical treatment, can produce large amounts of chemical sludge, which may pollute the environment in further treatment (Elouear et al. 2008). Hence, there was a need for economical, less toxic, renewable, sustainable, and easily operated techniques for the removal of heavy metal ions from wastewater (Crini 2005). Adsorption is an effective, energy-saving, and easily operated method for removing trace concentrations of contaminants, including heavy metals, from water. Its application to agricultural and industrial residues for the removal of heavy metals from water has been a focus of research in recent decades (Chand and Pakade 2015; Liang et al. 2018). 
The chemical formula of hydroxyapatite (HAP) is $\mathrm{Ca}_{10}\left(\mathrm{PO}_{4}\right)_{6}(\mathrm{OH})_{2}$, the most stable calcium hydrogen phosphate compound with $\mathrm{pH}$ from 4 to 12 , and the mole ratio of calcium to phosphorus is 1.67. This crystal chemical characteristic enables different types of heavy metals to replace the position of calcium in hydroxyapatite, so it has good ion adsorption and exchange characteristics. Recently, HAP has attracted considerable interest in the environmental field because of its high removal capacity for various heavy metals, e.g., $\mathrm{Pb}(\mathrm{II}), \mathrm{Cu}(\mathrm{II})$, and $\mathrm{Cd}(\mathrm{II})$, from water bodies (Saber-Samandari et al. 2014; Yan et al. 2014; Jayakodiarachchi and Jayaweera 2015). Hydroxylapatite and its composites have been reported as adsorbents for the removal of $\mathrm{Co}(\mathrm{II}), \mathrm{Ni}(\mathrm{II})$, and $\mathrm{Pb}(\mathrm{II})$ as well as organic compounds from aqueous solutions (Gupta et al. 2012). In Chand's work, hydroxyapatite nanoparticles were synthesized, and removal of $\mathrm{Pb}(\mathrm{II}), \mathrm{Cd}(\mathrm{II})$, and $\mathrm{Ni}(\mathrm{II})$ has been investigated. Langmuir models are fitted equally well the adsorption data for three ions under consideration, maximum adsorption capacity followed the order: $\mathrm{Pb}$ (II) $>\mathrm{Cd}$ (II) $>$ Ni(II) (Chand and Pakade 2015).

However, hydroxylapatite-based materials have weak mechanical strength. Moreover, the separation of HAP nanoparticles from the treated effluents is costprohibitive, time-consuming, and difficult to perform. Subsequently, the current challenges can be solved by coating HAP on to a fibrous network of highly porous bagasse, which produces a system that overcomes the hindrances associated with the physical characters of the nanomaterials, i.e., solid/liquid separation, poor mechanical strength, and small particle size. The annual bagasse production was approximately 200 million tons globally (Satyanarayana et al. 2007). Since the primary components of bagasse are cellulose, hemicellulose, and lignins, it was an ideal material for preparing a biomass adsorbent. In addition, hydroxyapatite bagasse biochar (HAP-BC) was used to adsorb As(V) in previous work (Yan et al. 2019). However, HAP-BC for lead removal has not been reported.

In this study, hydroxylapatite bagasse biochar (HAP-BC), with bagasse as the primary raw material, was prepared and the $\mathrm{Pb}(\mathrm{II})$ adsorption characteristics of HAP-BC were studied. The effect of various factors, e.g, contact time, $\mathrm{pH}, \mathrm{Pb}$ (II) concentration, and bagasse content, on the metal adsorption capacity of HAP-BC were studied using a series of batch experiments. The Langmuir adsorption isotherm and surface complex formation model were used to describe the adsorption characteristics of $\mathrm{Pb}(\mathrm{II})$ via aqueous HAP-BC.

\section{EXPERIMENTAL}

\section{Materials}

The calcium oxalate, sodium hydroxide, hydrochloric acid, ammonia, and lead nitrate were all analytical grade. The ammonium acetate and ammonium dihydrogen phosphate were all reagent grade. Bagasse, with marrow, was obtained from a sugar industry in Guigang, Guangxi, China.

\section{Preparation of HAP-BC}

Preparation of the HAP-BC and SB-BC (sugarcane bagasse biochar) are outlined in the supporting information $\mathrm{S} 1$ from the authors' earlier work (Yan et al. 2019). Figure 1 shows the preparation flow chart of the HAP-BC. 


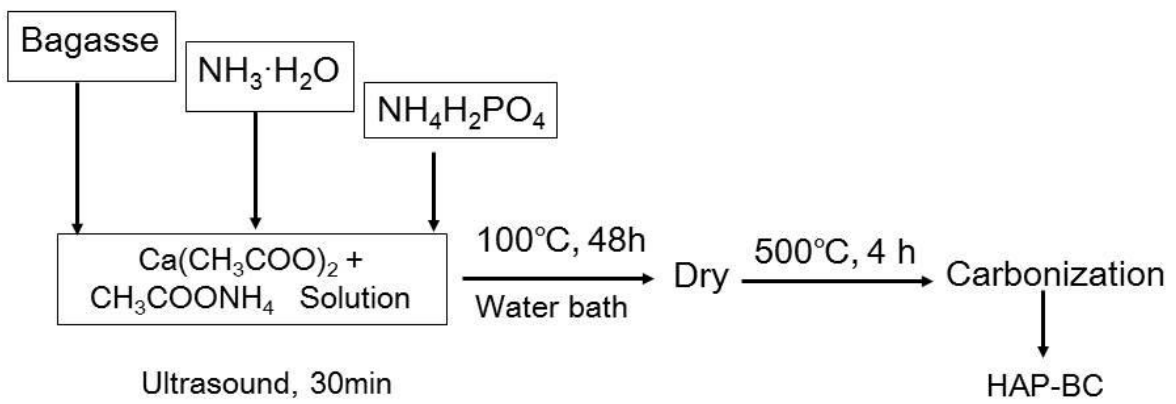

Fig. 1. The preparation flow chart of the HAP-BC

\section{Characterization of HAP-BC}

The as-prepared HAP-BC sample was systematically analyzed via scanning electron microscopy (SEM) (JSM-6380LV, JEOL Ltd., Tokyo, Japan), energy dispersive X-ray spectroscopy (EDS) (JEM-6380LV, JEOL Ltd., Tokyo, Japan), scanning electron microscopy (TEM, JSM-6380LV, JEOL, Japan), Fourier transform infrared spectroscopy (FT-IR) (CAT500A, PerkinElmer, Waltham, MA), X-ray photoelectron spectroscopy (XPS) (Thermo Fisher Scientific Inc., Waltham, MA), and X-ray diffraction (XRD) (X'Pert PRO X, Malvern Panalytical, Malvern, UK). The specific surface area was determined according to the Brunauer-Emmet-Teller (BET) equation using a Quantachrome Nova Station apparatus (Beijing Jingwei Gaobo Science and Technology Co., Ltd., Beijing, China). The pH was recorded with a pH meter (PHM250). Furthermore, the zeta potential was measured as a function of the $\mathrm{pH}$ in a $\mathrm{NaCl}$ electrolyte solution with a Malvern Zetasizer Nano ZS90 (Malvern Panalytical Ltd, Malvern, England). The XPS experiments were performed with a ESCALAB 250Xi (Thermo Electron Corporation, Waltham, USA) using an $\mathrm{Al} \mathrm{K} \alpha \mathrm{X}$-ray source $(1486.6 \mathrm{eV})$. The residual $\mathrm{Pb}$ (II) concentration was determined via atomic absorption spectrometry (AAnalyst 700, PerkinElmer, Waltham, MA, USA).

\section{Batch Experiments}

The sorption performance of HAP-BC for $\mathrm{Pb}(\mathrm{II})$ was evaluated via the batch technique under different conditions. First, the desired amounts of HAP-BC powder were weighed and put into $100 \mathrm{~mL}$ plastic centrifuge tubes. Then, $50 \mathrm{~mL}$ of $\mathrm{Pb}$ (II) solution at different concentrations was added, after $\mathrm{pH}$ adjustments. The tubes were sealed with capsules and shaken with a temperature shaker $\left(\right.$ at $25{ }^{\circ} \mathrm{C}, 35^{\circ} \mathrm{C}$, and $45^{\circ} \mathrm{C}$ ) at $200 \mathrm{r} \cdot \mathrm{min}^{-1}$ overnight, allowing the adsorption to reach equilibrium. After centrifugation with 4000 $\mathrm{r} \cdot \mathrm{min}^{-1}$ for $5 \mathrm{~min}$, all the samples were filtered through a $0.45 \mu \mathrm{m}$ micropore membrane and spiked with $0.2 \%(\mathrm{~V} / \mathrm{V}) \mathrm{HNO}_{3}$ in $100 \mathrm{~mL}$ volumetric flasks.

The removal of $\mathrm{Pb}$ (II) on HAP-BC was calculated using Eq. 1,

$$
\operatorname{Removal}(\%)=\frac{C_{0}-C_{e}}{C_{0}} \times 100 \%
$$

where $C_{e}\left(\mathrm{mg} \cdot \mathrm{L}^{-1}\right)$ is the final concentration and $C_{0}\left(\mathrm{mg} \cdot \mathrm{L}^{-1}\right)$ is the initial concentration. The amount of $\mathrm{Pb}$ (II) loaded on the HAP-BC sample was determined by Eq. 2,

$$
Q_{e}=\frac{C_{0}-C_{e}}{m} \times V
$$


where $Q_{e}\left(\mathrm{mg} \cdot \mathrm{g}^{-1}\right)$ is the amount of loaded $\mathrm{Pb}(\mathrm{II}), V(\mathrm{~L})$ is the solution volume, and $m(\mathrm{mg})$ is the mass of the HAP-BC.

The following operating parameters that may affect $\mathrm{Pb}(\mathrm{II})$ adsorption were studied: the contact time (30 min to $2160 \mathrm{~min}$ ), the solution $\mathrm{pH}$ (2.0 to 9.0), the adsorbent dosage $\left(1.00 \mathrm{~g} \cdot \mathrm{L}^{-1}\right.$ to $\left.6.00 \mathrm{~g} \cdot \mathrm{L}^{-1}\right)$, the initial $\mathrm{Pb}(\mathrm{II})$ concentration $\left(10 \mathrm{mg} \cdot \mathrm{L}^{-1}\right.$ to $\left.500 \mathrm{mg} \cdot \mathrm{L}^{-1}\right)$, and temperature $\left(25^{\circ} \mathrm{C}\right.$ to $\left.45^{\circ} \mathrm{C}\right)$. The adsorption isotherm, the adsorption rate, and the thermodynamic parameters were obtained and analyzed at a $\mathrm{pH}$ of 7.0.

\section{Reusability Experiments}

Reusability experiments were used to test the stability and reusability of the HAPBC. The HAP-BC was magnetically separated and re-dispersed into $0.5 \mathrm{~mol} \mathrm{~L}^{-1}$ of a $\mathrm{Na}_{2} \mathrm{CO}_{3}$ solution for $6 \mathrm{~h}$, after reaching sorption equilibrium. The HAP-BC was used for regeneration experiments; it was washed with $0.1 \mathrm{~mol} \mathrm{~L}^{-1} \mathrm{HCl}$ solution and ultra-pure water three times, respectively. Then the regenerated HAP-BC was applied for the next cycle of sorption experiments.

\section{RESULTS AND DISCUSSION}

\section{Characteristics of Hydroxylapatite Bagasse Biochar Composite (HAP-BC)}

The size and shape of the hydroxylapatite (HAP) particles on the HAP-BC surface are shown in Fig. 2a. The size of the HAP particles ranged from 150 and $300 \mathrm{~nm}$. The XRD characterization of the HAP-BC was in agreement with the HAP reference in terms of both the peak position and relative intensity, which recorded diffraction peaks at $2 \theta=25.93^{\circ}$, $31.85^{\circ}, 39.86^{\circ}, 46.78^{\circ}, 49.45^{\circ}$, and $53.45^{\circ}$, which corresponded to the (002), (211), (130), (222), (213), and (004) facets of hydroxylapatite, respectively (Reference code 00-0011008), confirming the formation of HAP. The diffraction peak at $2 \theta=44.54^{\circ}$ belonged to carbon (Reference code 00-011-0646), i.e., a carbonization product of sintered bagasse (as shown in Fig. 2b).

The FTIR spectra of the HAP-BC, bagasse biochar, and activated carbon are shown in Fig. 2c. The absorption peaks of the HAP-BC, bagasse biochar, and activated carbon were at 3428,3413 , and $3391 \mathrm{~cm}^{-1}, 1600,1577$, and $1569 \mathrm{~cm}^{-1}$, and 1379,1386 , and 1379 $\mathrm{cm}^{-1}$, respectively. The $-\mathrm{OH}$ functional groups appeared at 3391 to $3428 \mathrm{~cm}^{-1}$ and the $\mathrm{C}=\mathrm{O}$ functional groups appeared at 1569 to $1600 \mathrm{~cm}^{-1}$. The peak at 1379 to $1386 \mathrm{~cm}^{-1}$ was the bending vibration of the $-\mathrm{COOH}$ and phenolic groups (Xu et al. 2008). The absorption peaks at 1036,601 , and $563 \mathrm{~cm}^{-1}$ were the symmetrical stretching vibrational peaks of a tetrahedron of $\mathrm{PO}_{4}{ }^{3-}$, while the spectra of the sugarcane bagasse biochar and activated carbon exhibited no adsorption peaks at the same wavenumber $\left(1036,601\right.$, and $\left.563 \mathrm{~cm}^{-1}\right)$. The FTIR absorption peaks of the HAP-BC were at 1097 and $1036 \mathrm{~cm}^{-1}$, which were characteristic of hydroxylapatite, further confirming the formation of HAP (Corami et al. 2008). The oxygen-containing functional groups were abundantly present on the external and internal surfaces of the HAP-BC, as the adsorption sites contributed to the ion adsorption capacity of HAP-BC.

The specific surface area of HAP-BC was $89.52 \mathrm{~m}^{2} \cdot \mathrm{g}^{-1}$ (Yan et al. 2019), which was determined by the BET $\mathrm{N}_{2}$ adsorption method. At the same carbonization temperature, the specific surface area of HAP-BC was approximately 6, 10, 2.5, 2, and 10 times that of spruce, white poplar, rice husk, orange peel, and magnetic modified oak biomass carbon, respectively (Kloss et al. 2012; Liu et al. 2012). The average pore diameter and total pore 
volume were $1.25 \mathrm{~nm}$ and $29.26 \mathrm{~cm}^{3} \cdot \mathrm{g}^{-1}$, respectively.

The zeta potential as a function of $\mathrm{pH}$ is shown in Fig. $\mathrm{S} 1$, the $\mathrm{pH}_{\mathrm{zpc}}$ was 7.1 and 4.40 for HAP-BC and bagasse biochar, respectively. The $\mathrm{pH}_{\mathrm{zpc}}$ of HAP-BC was lower than the $\mathrm{pH}_{\mathrm{zpc}}$ of cellulose carbonate hydroxylapatite composite and most commercial activated carbons, but higher than the $\mathrm{pH}_{\mathrm{zpc}}$ of bagasse biochar (De and Ellerbroek 1994; Corapcioglu and Huang 1987).

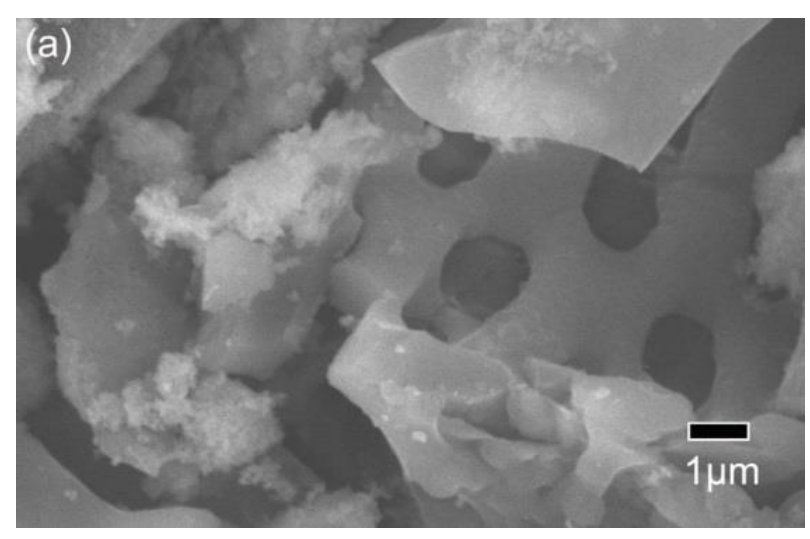

(b)

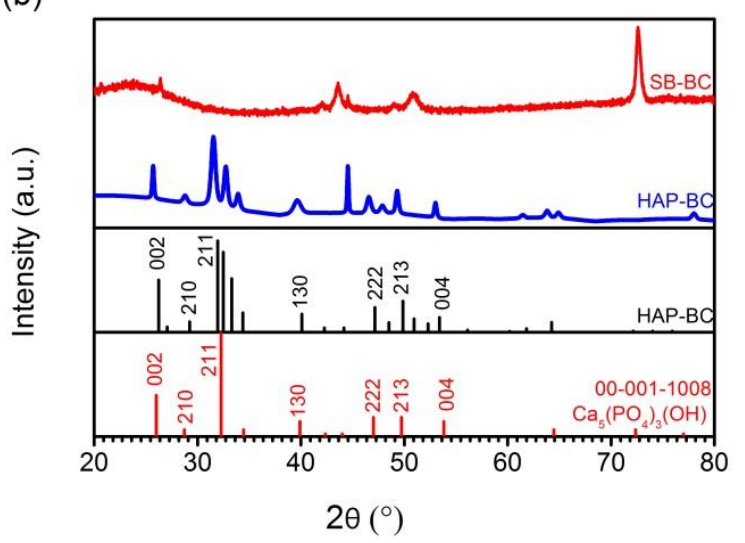

(c)

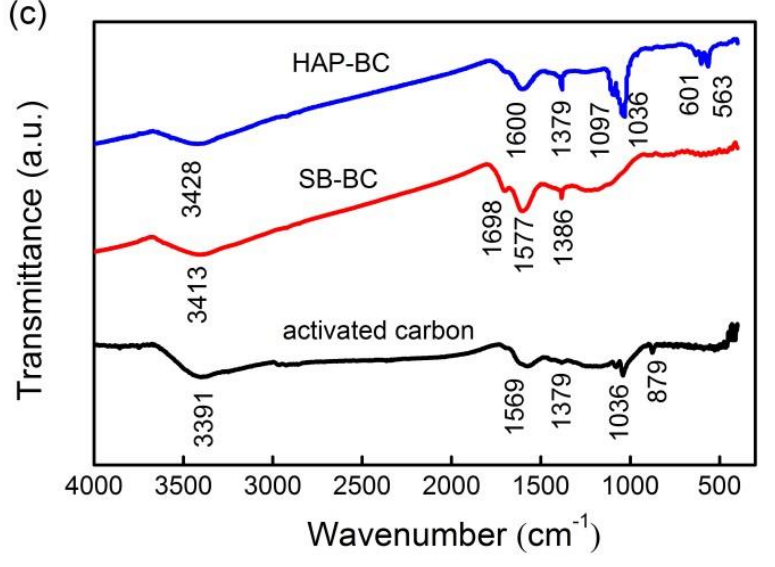

Fig. 2. SEM (a), XRD (b), and FTIR (c) of the HAP-BC

\section{Major Factors Affecting Pb(II) Adsorption}

The $\mathrm{pH}$ of the wastewater influences the adsorption performance of HAP-BC in terms of $\mathrm{Pb}(\mathrm{II})$, as shown in Fig. 3a. At $C_{0}$ equal to $100 \mathrm{mg} \cdot \mathrm{L}^{-1}$, the $\mathrm{Pb}(\mathrm{II})$ adsorption capacity was increased from $24.1 \mathrm{mg} \cdot \mathrm{g}^{-1}$ to $49.0 \mathrm{mg} \cdot \mathrm{g}^{-1}$ by the $\mathrm{pH}$ was increased from 2.0 to 7.0 . In addtion, at $C_{0}$ equal to $400 \mathrm{mg} \cdot \mathrm{L}^{-1}$, the $\mathrm{Pb}$ (II) adsorption capacity was increased between $163.7 \mathrm{mg} \cdot \mathrm{g}^{-1}$ and $199.2 \mathrm{mg} \cdot \mathrm{g}^{-1}$ as the $\mathrm{pH}$ was increased from 2.0 to 7.0 . In a word, the optimum $\mathrm{pH}$ was in the range of 4.0 to 7.0 .

In addition, the nature of the surface charge could play a role in $\mathrm{Pb}$ (II) adsorption (Sreejalekshmi et al. 2009). At a $\mathrm{pH}$ less than the $\mathrm{pH}_{\mathrm{zpc}}$, the adsorbent surface was positively charged, such that there was a strong electrostatic repulsion between the surface groups and the $\mathrm{Pb}(\mathrm{II})$ species (Sreejalekshmi et al. 2009). At a $\mathrm{pH}$ less than 7.0, the predominant $\mathrm{Pb}$ (II) species was $\mathrm{Pb}^{2+}$, with a strong electrostatic repulsion between the positively charged HAP-BC and the cationic $\mathrm{Pb}$ (II) species, as expected, which had no benefit to $\mathrm{Pb}(\mathrm{II})$ adsorption via the HAP-BC. However, the results showed that the optimum $\mathrm{pH}$ was in the range from 4.0 to 7.0. Therefore, one can conclude, that additional 
forces other than the electrostatic attraction, e.g., dissolution/precipitation and surface complexation, contributed to $\mathrm{Pb}$ (II) adsorption (Feng et al. 2009).
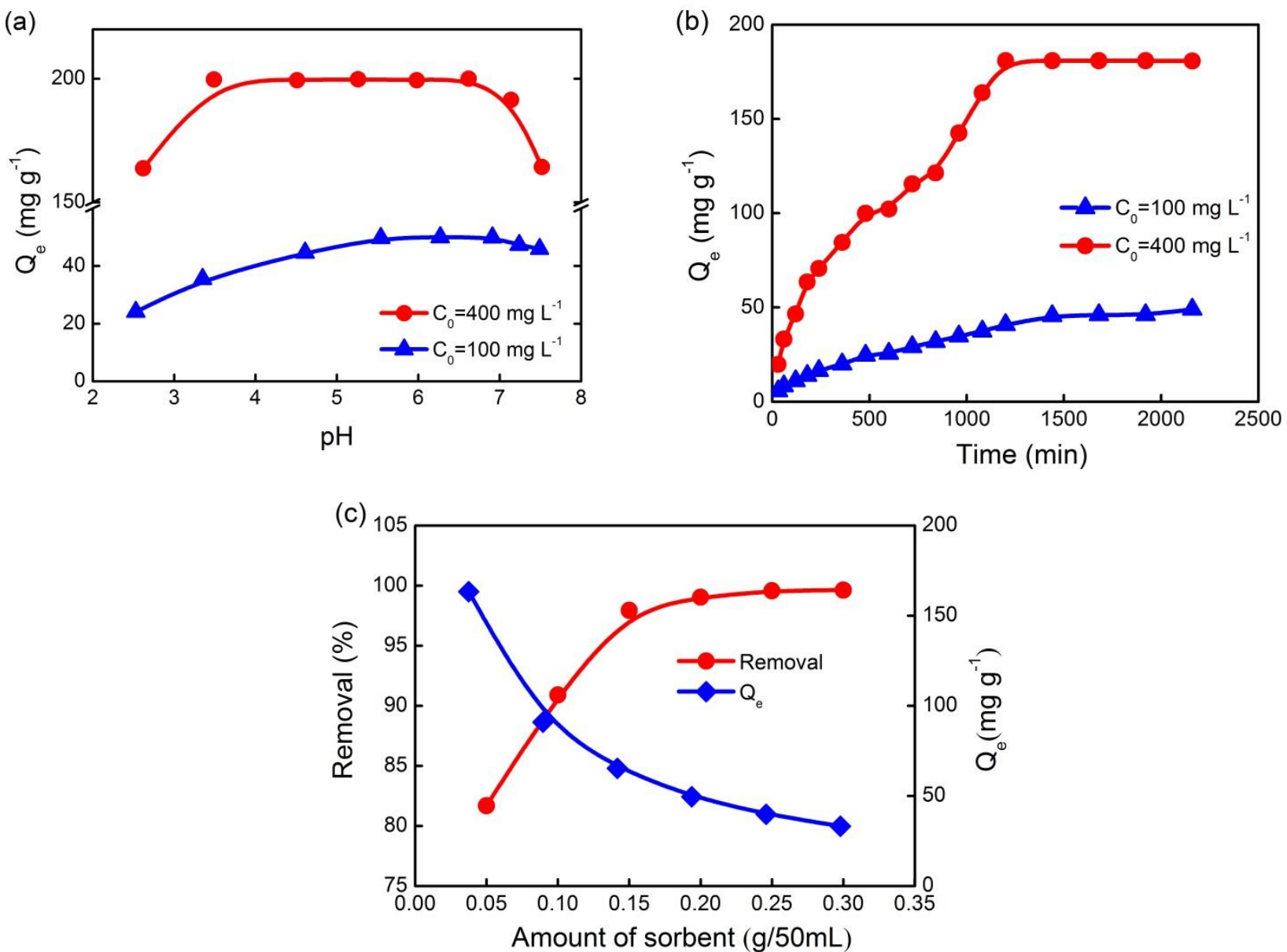

Fig. 3. Major factors affecting the $\mathrm{Pb}(\mathrm{II})$ adsorption by HAP-BC: (a) $\mathrm{pH}$, (b) contact time, and (c) adsorbent dose. Experimental conditions: temperature of $25^{\circ} \mathrm{C}$; for (b) the $\mathrm{pH}$ was 5.0

The mechanism of dissolution is shown in Eq. 3,

$$
\mathrm{Ca} 5\left(\mathrm{PO}_{4}\right)_{3}(\mathrm{OH})(\mathrm{s}) \rightarrow 5 \mathrm{Ca}^{2+}+3 \mathrm{PO}_{4}{ }^{3-}+\mathrm{OH}^{-}
$$

and the precipitation mechanism is shown in Eq. 4,

$$
3 \mathrm{~Pb}^{2+}+2 \mathrm{PO}_{4}{ }^{3-}+\mathrm{OH}^{-} \rightarrow \mathrm{Pb}_{3}\left(\mathrm{PO}_{4}\right)_{2}(\mathrm{~s})
$$

After the dissolution of $\mathrm{Ca}^{2+}$, HAP-BC, hydroxyapatite, and $\mathrm{Pb}$ (II) formed a more stable lead phosphate, which was more conducive to the removal of $\mathrm{Pb}^{2+}$, while the effect of $\mathrm{Ca}^{2+}$ could be ignored $\left(\mathrm{K}_{\mathrm{sp}}\left[\mathrm{Pb}_{3}\left(\mathrm{PO}_{4}\right)_{2}\right]=8.0 \times 10^{-43}, \mathrm{~K}_{\mathrm{sp}}\left[\mathrm{Ca}_{3}\left(\mathrm{PO}_{4}\right)_{2}\right]=1.0 \times 10^{-25}\right)$ (Srinivasan et al. 2006; Feng et al. 2009).

Table 1 shows the concentration of $\mathrm{Ca}^{2+}, \mathrm{PO}_{4}{ }^{3-}$, and the $\mathrm{Ca}$ to $\mathrm{P}$ molar ratio at different pHs. There was a decrease in the concentration of $\mathrm{Ca}^{2+}$ and $\mathrm{PO}_{4}{ }^{3-}$ as the $\mathrm{pH}$ increased from 2.1 to 9.3. In addition, the $\mathrm{Ca}$ to $\mathrm{P}$ molar ratio increased from 4.5 to 36.8 at an initial $\mathrm{Pb}$ (II) concentration of $100 \mathrm{mg} \cdot \mathrm{L}^{-1}$. However, at an initial $\mathrm{Pb}(\mathrm{II})$ concentration of $400 \mathrm{mg} \mathrm{L}^{-1}$, the calcium to phosphorus molar ratio in the solution increased from 17.0 to 42.7 within a $\mathrm{pH}$ range of 2.1 to 6.8 , but decreasing from 42.67 to 16.00 when the $\mathrm{pH}$ 
increased from 6.8 to 9.3 . At a $\mathrm{pH}$ less than 6.8 , the calcium to phosphorus molar ratio at an initial $\mathrm{Pb}$ (II) concentration of $400 \mathrm{mg} \cdot \mathrm{L}^{-1}$ was greater than the calcium to phosphorus molar ratio at an initial $\mathrm{Pb}(\mathrm{II})$ concentration of $100 \mathrm{mg} \cdot \mathrm{L}^{-1}$ at the same $\mathrm{pH}$ value, which was far greater than the theoretical $\mathrm{Ca}$ to $\mathrm{P}$ molar ratio of hydroxylapatite (1.67). It was confirmed that the $\mathrm{Pb}(\mathrm{II})$ adsorption mechanism of HAP-BC included ion exchange, dissolution/precipitation, and surface complexation working together (Feng et al. 2009).

Table 1. Effect of the pH on Hydroxylapatite Bagasse Biochar Composite (HAP$\mathrm{BC})$ Ion Concentrations

\begin{tabular}{|c|c|c|c|c|c|c|}
\hline \multirow{3}{*}{$\mathrm{pH}$} & \multirow{2}{*}{\multicolumn{2}{|c|}{$\begin{array}{c}\text { Calcium Concentration } \\
\left(\mathrm{mmol} \cdot \mathrm{L}^{-1}\right) \\
C_{0}(\mathrm{~Pb})\left(\mathrm{mg} \cdot \mathrm{L}^{-1}\right) \\
\end{array}$}} & \multirow{2}{*}{\multicolumn{2}{|c|}{$\begin{array}{l}\text { Phosphate Concentration } \\
\left(\mathrm{mmol} \cdot \mathrm{L}^{-1}\right) \\
C_{0(\mathrm{~Pb})}\left(\mathrm{mg} \cdot \mathrm{L}^{-1}\right) \\
\end{array}$}} & \multirow{2}{*}{\multicolumn{2}{|c|}{$\begin{array}{c}\text { Calcium to Phosphorus } \\
\text { Molar Ratio } \\
C_{0(\mathrm{~Pb})}\left(\mathrm{mg} \cdot \mathrm{L}^{-1}\right)\end{array}$}} \\
\hline & & & & & & \\
\hline & 100 & 400 & 100 & 400 & 100 & 400 \\
\hline 2.1 & 7.12 & 7.30 & 1.57 & 0.43 & 4.54 & 16.98 \\
\hline 3.1 & 1.85 & 4.78 & 0.46 & 0.27 & 4.06 & 17.70 \\
\hline 4.0 & 1.27 & 3.69 & 0.18 & 0.18 & 7.24 & 20.50 \\
\hline 5.1 & 1.06 & 3.27 & 0.13 & 0.08 & 8.30 & 40.88 \\
\hline 6.1 & 1.01 & 2.89 & 0.09 & 0.07 & 10.75 & 41.29 \\
\hline 6.8 & 0.90 & 2.56 & 0.07 & 0.06 & 12.80 & 42.67 \\
\hline 7.9 & 0.73 & 1.23 & 0.03 & 0.05 & 34.44 & 24.60 \\
\hline 9.3 & 1.03 & 1.12 & 0.03 & 0.07 & 36.80 & 16.00 \\
\hline
\end{tabular}

When the $\mathrm{Pb}(\mathrm{II})$ concentration was 100 and $400 \mathrm{mg} \cdot \mathrm{L}^{-1}$, the $\mathrm{Pb}$ (II) was sorbed within the first $500 \mathrm{~min}$ at average sorption rates of 0.0319 and $0.0754 \mathrm{mg} \cdot \mathrm{g}^{-1} \mathrm{~min}^{-1}$, respectively. The rapid sorption rate was typical of ion adsorption from aqueous solutions and indicative of favoured interactions between the HAP-BC and $\mathrm{Pb}$ (II). The results shown in Fig. $3 \mathrm{~b}$ also showed that the amount of $\mathrm{Pb}$ (II) adsorption reached a plateau at 1200 and $1400 \mathrm{~min}$ at the initial $\mathrm{Pb}(\mathrm{II})$ concentrations of 100 and $400 \mathrm{mg} \cdot \mathrm{L}^{-1}$, respectively. Mondal et al. (2007) reported that the adsorption reaction rapidly occurred during the initial stage, which was followed by a slow reaction until adsorption equilibrium was reached.

When maintaining the contact time, $\mathrm{pH}$, and initial $\mathrm{Pb}$ (II) concentration constant at $25{ }^{\circ} \mathrm{C}$, the adsorption of $\mathrm{Pb}$ (II) by the HAP-BC was studied by changing the amount of adsorbent in the test solution (Fig. 3c). Increasing the adsorbent dose was attributed to increasing the surface area and availability of additional adsorption sites, but the amount of $\mathrm{Pb}$ (II) absorbed per unit mass of the adsorbent decreased from 163.4 to $32.2 \mathrm{mg} \cdot \mathrm{g}^{-1}$ as the adsorbent dose increased. The percentage of $\mathrm{Pb}(\mathrm{II})$ removed from the solution increased from $81.9 \%$ to $99.6 \%$ as the HAP-BC dosage increased from 0.05 to $0.30 \mathrm{~g}$ in a $50 \mathrm{~mL}$ solution. At the same time, the $\mathrm{pH}$ of the solution at adsorption equilibrium decreased from 4.26 to 4.16 as the HAP-BC dose increased from $0.05 \mathrm{~g}$ to $0.30 \mathrm{~g}$ in a $50 \mathrm{~mL}$ solution.

\section{Adsorption Isotherm}

The $\mathrm{Pb}(\mathrm{II})$ adsorption isotherm is shown Fig. 4, in which SB-BC and HAP-BC are at a different temperature. At a temperature of 25,35 and $45^{\circ} \mathrm{C}$, the $\mathrm{Pb}$ (II) adsorption capacity quickly increased as the equilibrium $\mathrm{Pb}(\mathrm{II})$ concentration increased when it was lesser than $20 \mathrm{mg} \cdot \mathrm{L}^{-1}$. The $\mathrm{Pb}$ (II) adsorption capacity slowly increased when the equilibrium $\mathrm{Pb}(\mathrm{II})$ concentration increased when it was greater than $20 \mathrm{mg} \cdot \mathrm{L}^{-1}$. The equilibrium adsorption capacity of $\mathrm{HAP}-\mathrm{BC}$ to $\mathrm{Pb}(\mathrm{II})$ at temperatures of 25,35 , and $45^{\circ} \mathrm{C}$ were 193,202 , and $206 \mathrm{mg} \cdot \mathrm{g}^{-1}$, respectively. It was interesting to note that HAP-BC exhibited a $\mathrm{Pb}(\mathrm{II})$ adsorption capacity thirty times that of SB-BC. 


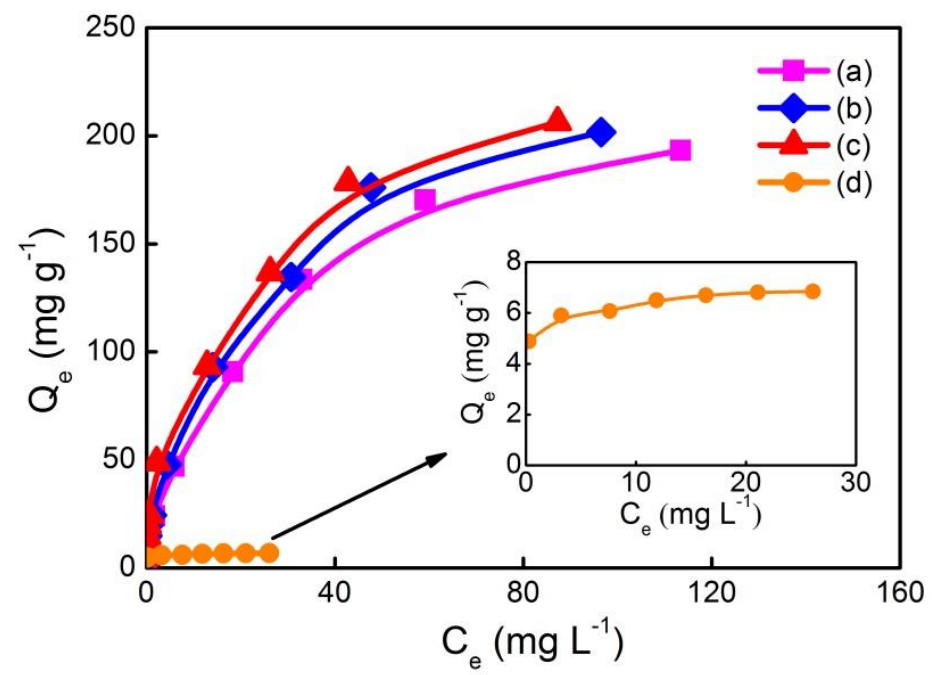

Fig. 4. Langmuir adsorption isotherm of $\mathrm{Pb}(\mathrm{II})$ on $\mathrm{HAP}-\mathrm{BC}$ at different temperature $(\mathrm{pH}=5.0)$ : (a) HAP-BC adsorbed $\mathrm{Pb}$ (II) at $25^{\circ} \mathrm{C}$; (b) HAP-BC adsorbed $\mathrm{Pb}$ (II) at $35^{\circ} \mathrm{C}$; (c )HAP-BC adsorbed $\mathrm{Pb}$ (II) at $45{ }^{\circ} \mathrm{C}$; and (d) SB-BC adsorbed $\mathrm{Pb}$ (II) at $25^{\circ} \mathrm{C}$

The $\mathrm{Pb}$ (II) adsorption density can be well described by the Langmuir adsorption isotherm shown in Eq. 5,

$$
q=\frac{q_{\max } C_{e} K_{L}}{1+C_{e} K_{L}}
$$

where $q$ is the adsorption density $\left(\mathrm{mg} \cdot \mathrm{g}^{-1}\right), q_{\max }$ is the monolayer-layer adsorption density $\left(\mathrm{mg} \cdot \mathrm{g}^{-1}\right), K_{L}$ is the Langmuir constant $\left(\mathrm{M}^{-1}\right)$, and $C_{e}$ is the equilibrium concentration (as shown in Fig. S3).

The data were found to fit Eq. 5, with a coefficient of determination $\left(\mathrm{R}^{2}\right)$ of 0.980 , 0.981 , and 0.980 , at a temperature of 25,35 , and $45{ }^{\circ} \mathrm{C}$, respectively. In addition, the adsorption capacity increased from $210 \mathrm{mg} \cdot \mathrm{g}^{-1}$ (at $25{ }^{\circ} \mathrm{C}$ ) to $216 \mathrm{mg} \cdot \mathrm{g}^{-1}$ (at $45{ }^{\circ} \mathrm{C}$ ) (as shown in Table 2).

Table 2. Langmuir Isotherms Parameters for $\mathrm{Pb}$ (II) Adsorption by Hydroxylapatite Bagasse Biochar Composite (HAP-BC)

\begin{tabular}{|c|c|c|c|c|}
\hline Item & $q_{\mathrm{m}}\left(\mathrm{mg} \cdot \mathrm{g}^{-1}\right)$ & $K_{\mathrm{L}}\left(\mathrm{M}^{-1}\right)$ & $\mathrm{R}^{2}$ & $\Delta G\left(\mathrm{~kJ} \cdot \mathrm{mol}^{-1}\right)$ \\
\hline SB-BC $\left(25^{\circ} \mathrm{C}\right)$ & 6.94 & $4.90 \times 10^{-7}$ & 0.999 & -39.49 \\
\hline HAP-BC $\left(25^{\circ} \mathrm{C}\right)$ & 209.6 & $1.68 \times 10^{-6}$ & 0.980 & -35.53 \\
\hline HAP-BC $\left(35^{\circ} \mathrm{C}\right)$ & 213.7 & $1.72 \times 10^{-6}$ & 0.981 & -36.78 \\
\hline HAP-BC $\left(45^{\circ} \mathrm{C}\right)$ & 216.5 & $2.88 \times 10^{-6}$ & 0.980 & -39.34 \\
\hline
\end{tabular}

These results indicated that the $\mathrm{Pb}(\mathrm{II})$ adsorption by HAP-BC was an endothermic reaction. In addition, HAP-BC exhibited a $\mathrm{Pb}(\mathrm{II})$ adsorption capacity of $210 \mathrm{mg} \cdot \mathrm{g}^{-1}$, which was greater than the $\mathrm{Pb}(\mathrm{II})$ adsorption capacity of sorghum biochar $\left(17.8 \mathrm{mg} \cdot \mathrm{g}^{-1}\right)$, and it was four times greater than the $\mathrm{Pb}(\mathrm{II})$ adsorption capacity of bamboo biochar $\left(55.6 \mathrm{mg} \cdot \mathrm{g}^{-}\right.$ 1) (Wang et al. 2012). Compared to other literature (Naushad 2014; Naushad et al. 2014; Naushad et al. 2015), the comparison of maximum monolayer adsorption capacities $\left(Q_{\mathrm{m}}\right)$ of $\mathrm{Pb}(\mathrm{II})$ ion on different adsorbents are given in Table 3. 
Table 3. Comparison of Maximum Monolayer Adsorption Capacity of $\mathrm{Pb}$ (II) ion using Various Adsorbents

\begin{tabular}{|c|c|c|}
\hline Adsorbents & $\begin{array}{c}\text { Maximum monolayer } \\
\text { adsorption capacity } Q_{\mathrm{m}}\left(\mathrm{mg} \mathrm{g}^{-1}\right)\end{array}$ & References \\
\hline corn straws graphene oxide biochar & 26.1 & Zhang et al. 2018 \\
\hline cotton stalk-derived biochar & 147 & $\begin{array}{c}\text { Gao et al. 2021 } \\
\text { 2021 } \text { et al. }\end{array}$ \\
\hline canola straw biochar & 165 & Xu et al. 2021 \\
\hline $\mathrm{KH}_{2}$ PO 4 -modified biochar & 154.7 & Zhang et al. 2018 \\
\hline sludge-based biochar & 16.70 & Kwak et al. 2019 \\
\hline canola straw biochar & 108 & Kwak et al. 2019 \\
\hline wheat straw biochar & 109 & Yan et al. 2020 \\
\hline bean-worm skin biochar & 62 & $\begin{array}{c}\text { Bardestani et al. } \\
2019\end{array}$ \\
\hline mild air oxidation biochar & 44 & Yang et al. 2019 \\
\hline Enteromorpha biochar & 98 & Fu et al. 2020 \\
\hline $\begin{array}{c}\text { corncob biochar based } \\
\text { montmorillonite composite }\end{array}$ & 140 & Present work \\
\hline hydroxylapatite bagasse biochar & 216 & \\
\hline
\end{tabular}

However, the $\mathrm{Pb}(\mathrm{II})$ adsorption capacity of HAP-BC was much greater than the $\mathrm{Pb}$ (II) adsorption capacity of SB-BC at a temperature of $25^{\circ} \mathrm{C}\left(7.04 \mathrm{mg} \cdot \mathrm{g}^{-1}\right)$. The $K_{\mathrm{L}}$ values were $1.68 \times 10^{-6}, 1.72 \times 10^{-6}$, and $2.88 \times 10^{-6} \mathrm{M}^{-1}$ at 25,35 , and $45^{\circ} \mathrm{C}$, respectively. The change in the Gibbs free energy $(\Delta G)$ of the HAP-BC adsorption of $\mathrm{Pb}$ (II) can be calculated from the Nernst equation, as shown in Eq. 6,

$$
\Delta G=R T \ln K_{L}
$$

where $R$ is the gas constant $\left(8.314 \mathrm{~J} \mathrm{~mol}^{-1} \cdot \mathrm{K}^{-1}\right)$ and $T$ is the absolute temperature $(\mathrm{K})$. The $\Delta G$ (as shown in Table 2) indicated the spontaneous nature of $\mathrm{Pb}(\mathrm{II})$ adsorption by HAP$\mathrm{BC}$.

\section{Adsorption Kinetics}

Among different kinetic models, the experimental data could be best fit to the internal-particle diffusion kinetic model. According to the intra-particle diffusion model proposed by Weber-Morris (Naushad 2014; Naushad et al. 2014), the root time dependence may be expressed as Eq. 7 ,

$$
q_{t}=k_{i} t^{1 / 2}
$$

where $q_{t}$ is the adsorption capacity of HAP-BC at time $\mathrm{t}\left(\mathrm{mg} \cdot \mathrm{g}^{-1}\right), t$ is the time (min), and $k_{i}$ is the intraparticle diffusion rate constant $\left(\mathrm{mg} \cdot \mathrm{g}^{-1} \cdot \mathrm{min}^{-1 / 2}\right)$ (Crini 2008).

When the $\mathrm{Pb}(\mathrm{II})$ concentrations were 100 and $200 \mathrm{mg} \cdot \mathrm{L}^{-1}$, the intra-particle diffusion rate constants $k_{\mathrm{i}}$ were $1.14 \mathrm{mg} \cdot \mathrm{g}^{-1} \cdot \mathrm{min}^{-1 / 2}$ and $2.13 \mathrm{mg} \cdot \mathrm{g}^{-1} \cdot \mathrm{min}^{-1 / 2}$ and the correlation coefficients were 0.996 and 0.982 , respectively (as shown in Fig. S4 and Table 4). This indicated that the intra-particle diffusion kinetic model was suitable in terms of fitting the HAP-BC adsorption kinetics process of $\mathrm{Pb}(\mathrm{II})$, and the intra-particle diffusion process controls the primary steps of the adsorption of $\mathrm{Pb}(\mathrm{II})$ by HAP-BC. 
Table 4. Kinetic Parameters of $\mathrm{Pb}$ (II) Sorption by Hydroxylapatite Bagasse Biochar Composite (HAP-BC)

\begin{tabular}{|c|c|c|}
\hline $\mathrm{Pb}(\mathrm{II})$ Concentration $\left(\mathrm{mg} \cdot \mathrm{L}^{-1}\right)$ & $\mathrm{k}_{\mathrm{i}}\left(\mathrm{mg} \cdot \mathrm{g}^{-1} \cdot \mathrm{min}^{-1 / 2}\right)$ & $R^{2}$ \\
\hline 100.0 & 1.14 & 0.996 \\
\hline 200.0 & 2.31 & 0.982 \\
\hline
\end{tabular}

\section{Potential Adsorption Mechanism}

The X-ray diffraction analysis showed an obvious structural change (as shown in Fig. 5). The major carbon peaks were at $44.54^{\circ}$, which disappeared after $\mathrm{Pb}$ (II) adsorption occurred, which may be because the degree of crystallization of the organic charcoal in the bagasse carbonization product is lower. The major characteristic peaks $(2 \theta)$ of HAP-BC were shifted to a lower diffraction angle after $\mathrm{Pb}(\mathrm{II})$ adsorption occurred, compared with the major characteristic peaks before $\mathrm{Pb}(\mathrm{II})$ adsorption at $31.78^{\circ}, 39.83^{\circ}, 46.68^{\circ}$, and $53.55^{\circ}$, which was likely due to the complex adsorption reaction between HAP-BC and $\mathrm{Pb}$ (II). The diffraction peaks of lead hydroxylapatite (Reference code 00-001-0924) were recognized in the HAP-BC after $\mathrm{Pb}$ (II) adsorption occurred, which indicated that dissolution/precipitation and ion exchange reactions during the $\mathrm{Pb}$ (II) adsorption process by HAP-BC occurred. This may be the reason the solubility product constants of lead phosphate are much smaller than the solubility product constants of calcium phosphate $\left(\mathrm{K}_{\mathrm{sp}}\left[\mathrm{Pb}_{3}\left(\mathrm{PO}_{4}\right)_{2}\right]=8.0 \times 10^{-43}\right.$ versus $\left.\mathrm{K}_{\mathrm{sp}}\left[\mathrm{Ca}_{3}\left(\mathrm{PO}_{4}\right)_{2}\right]=1.0 \times 10^{-25}\right)$, and consequently, accompanied by the dissolution of HAP-BC, a more stable lead phosphate was formed (Srinivasan et al. 2006; Feng et al. 2009).

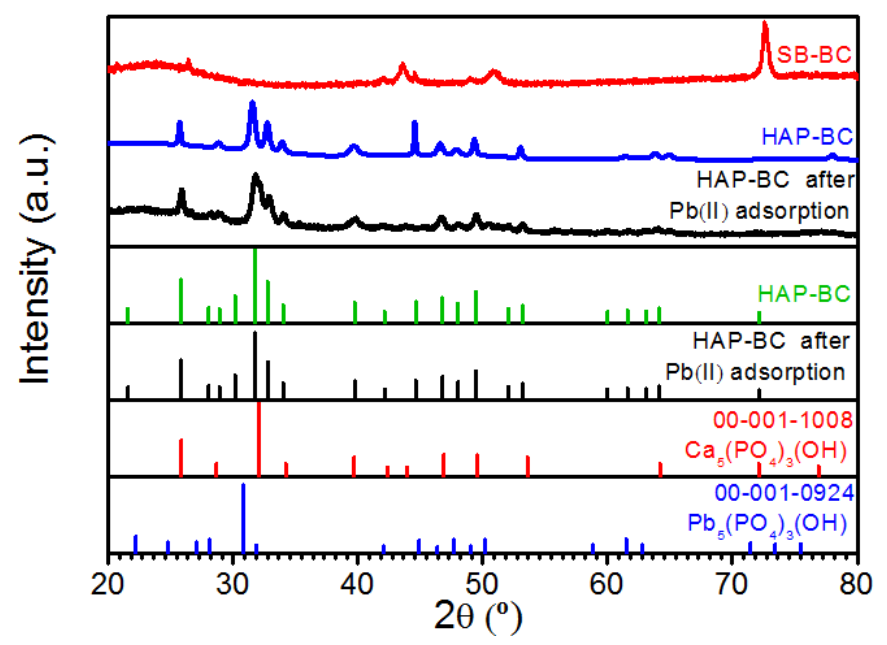

Fig. 5. XRD spectrogram of the HAP-BC before and after $\mathrm{Pb}(\mathrm{II})$ adsorption

To better understand the $\mathrm{Pb}(\mathrm{II})$ adsorption mechanism by HAP-BC, the amounts of $\mathrm{Pb}$ (II) adsorbed and the $\mathrm{Ca}^{2+}$ concentration, as well as the $\mathrm{pH}$ variation after adsorption, were measured by the adsorption isotherm experiments, as shown in Fig. 6a and 6b. It can be seen from Fig. 6 that the molar concentration of the released $\mathrm{Ca}^{2+}$ was not equal to the molar $\mathrm{Pb}$ (II) uptake by $\mathrm{HAP}-\mathrm{BC}$ as the initial $\mathrm{Pb}$ (II) concentration and the amounts of $\mathrm{Pb}$ (II) adsorbed increased. In addition, the difference between the amounts of $\mathrm{Pb}$ (II) adsorbed and $\mathrm{Ca}^{2+}$ released became larger as the initial $\mathrm{Pb}$ (II) concentration and the amounts of $\mathrm{Pb}$ (II) adsorbed increased, which suggested that the $\mathrm{Pb}$ (II) adsorption process may also be affected by other factors outside of dissolution and precipitation. 

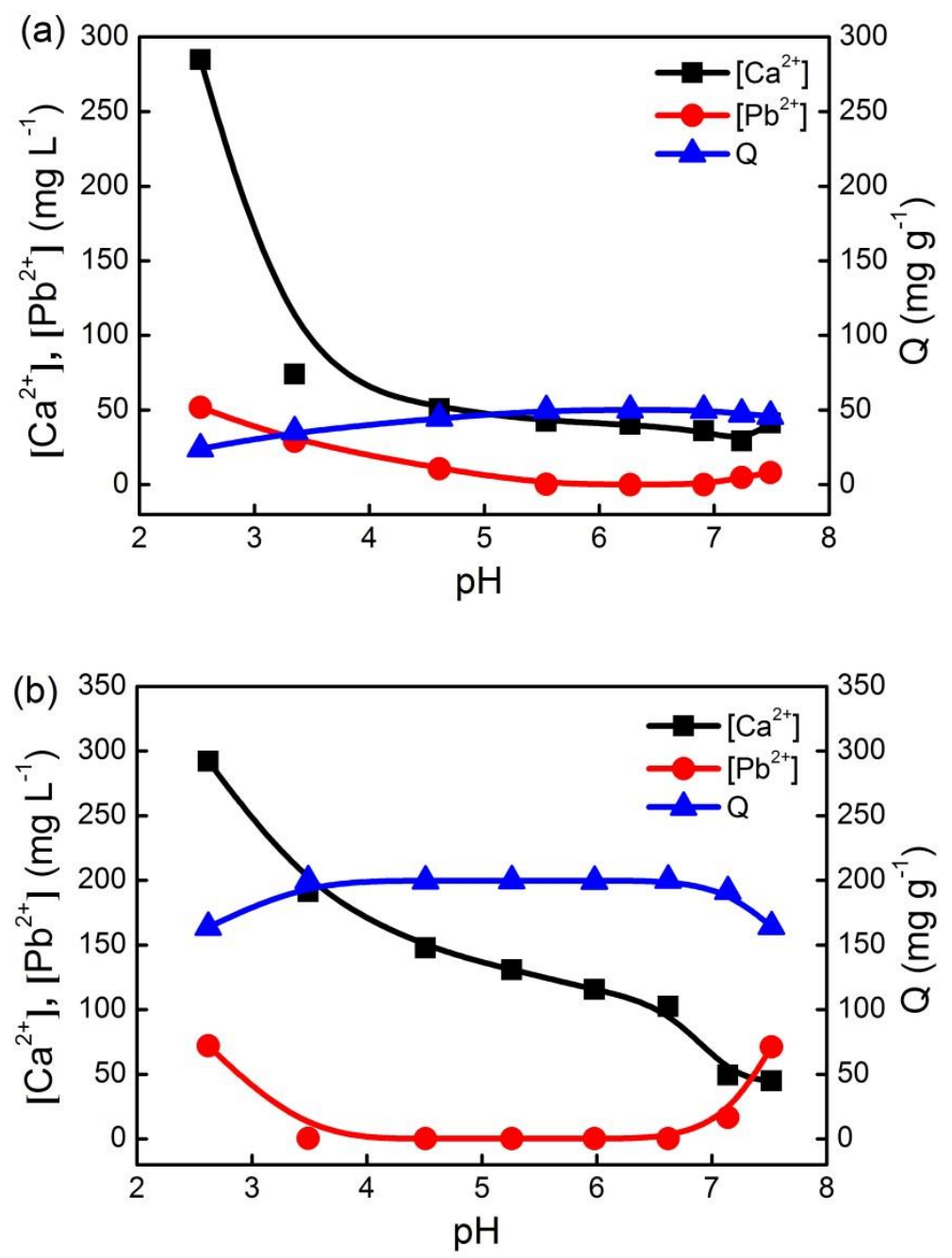

Fig. 6. The $\mathrm{pH}$ variation after adsorption was monitored via the adsorption of $\mathrm{Ca}^{2+}, \mathrm{Pb}^{2+}$, and $\mathrm{Q}_{\mathrm{e}}$ versus the $\mathrm{pH}$ : (a) $C_{0(\mathrm{~Pb})}=100 \mathrm{mg} \cdot \mathrm{L}^{-1}$; and $(\mathrm{b}) C_{0(\mathrm{~Pb})}=400 \mathrm{mg} \cdot \mathrm{L}^{-1}$

The XPS survey spectra of the HAP-BC and the HAP-BC after Pb(II) adsorption are shown in Fig. 7a. The observed photoelectron signals were $\mathrm{C} 1 \mathrm{~s}(276 \mathrm{eV}$ to $290 \mathrm{eV})$, O1s ( $522 \mathrm{eV}$ to $536 \mathrm{eV}$ ), Ca2p (340 eV to $355 \mathrm{eV}$ ), and P2p (125 eV to $145 \mathrm{eV}$ ). Phosphor constituted only accounted for $18.5 \%$ of the HAP chemical composition and its XPS sensitivity factor was relatively low, i.e., 22 (Moulder et al. 1995). The peak centered at 138.13 and $142.95 \mathrm{eV}$ (the HAP-BC spectrum after $\mathrm{Pb}$ (II) adsorption) was due to the $\mathrm{Pb}_{4} \mathrm{f}_{7 / 2}$ and $\mathrm{Pb} 4 \mathrm{f}_{5 / 2}$. The doublets characteristic of $\mathrm{Pb}$ in HAP-BC after $\mathrm{Pb}(\mathrm{II})$ adsorption appeared at $138.13 \mathrm{eV}$ (assigned to $\mathrm{Pb} 4 \mathrm{f}_{7 / 2}$ ) and at $142.95 \mathrm{eV}$ (assigned to $\mathrm{Pb} 4 \mathrm{f}_{5 / 2}$ ); the peak observed at $138.13 \mathrm{eV}$ agrees with the $138.4 \mathrm{eV}$ value reported for $\mathrm{Pb}(\mathrm{OH})_{2}$ by Lee et al. (2006), which indicated further complexation of Pb by HAP-BC and the precipitation of $\mathrm{Pb}$.

The atomic concentration (at.\%) of the adsorbent surface elements, as detected by XPS, was determined for the HAP-BC before and after $\mathrm{Pb}(\mathrm{II})$ adsorption (as shown in Fig. $7 \mathrm{~b}$ ). The amounts of $\mathrm{O}, \mathrm{Ca}, \mathrm{P}$, and $\mathrm{Pb}$ significantly increased after $\mathrm{Pb}$ (II) adsorption by HAP-BC, which revealed that the variation in the XPS analysis area was due to the illdefined porous structure of the resorbing HAP-BC layer. However, the amounts of $\mathrm{O}, \mathrm{Ca}$, $\mathrm{P}$, and $\mathrm{Pb}$ detected on the HAP-BC samples were observed to be less than the amounts of 
$\mathrm{O}, \mathrm{Ca}, \mathrm{P}$, and $\mathrm{Pb}$ detected on the HAP-BC samples after $\mathrm{Pb}(\mathrm{II})$ adsorption. This may also be explained by the variation in the XPS analysis area due to the ill-defined porous structure of the resorbing HAP-BC layer.
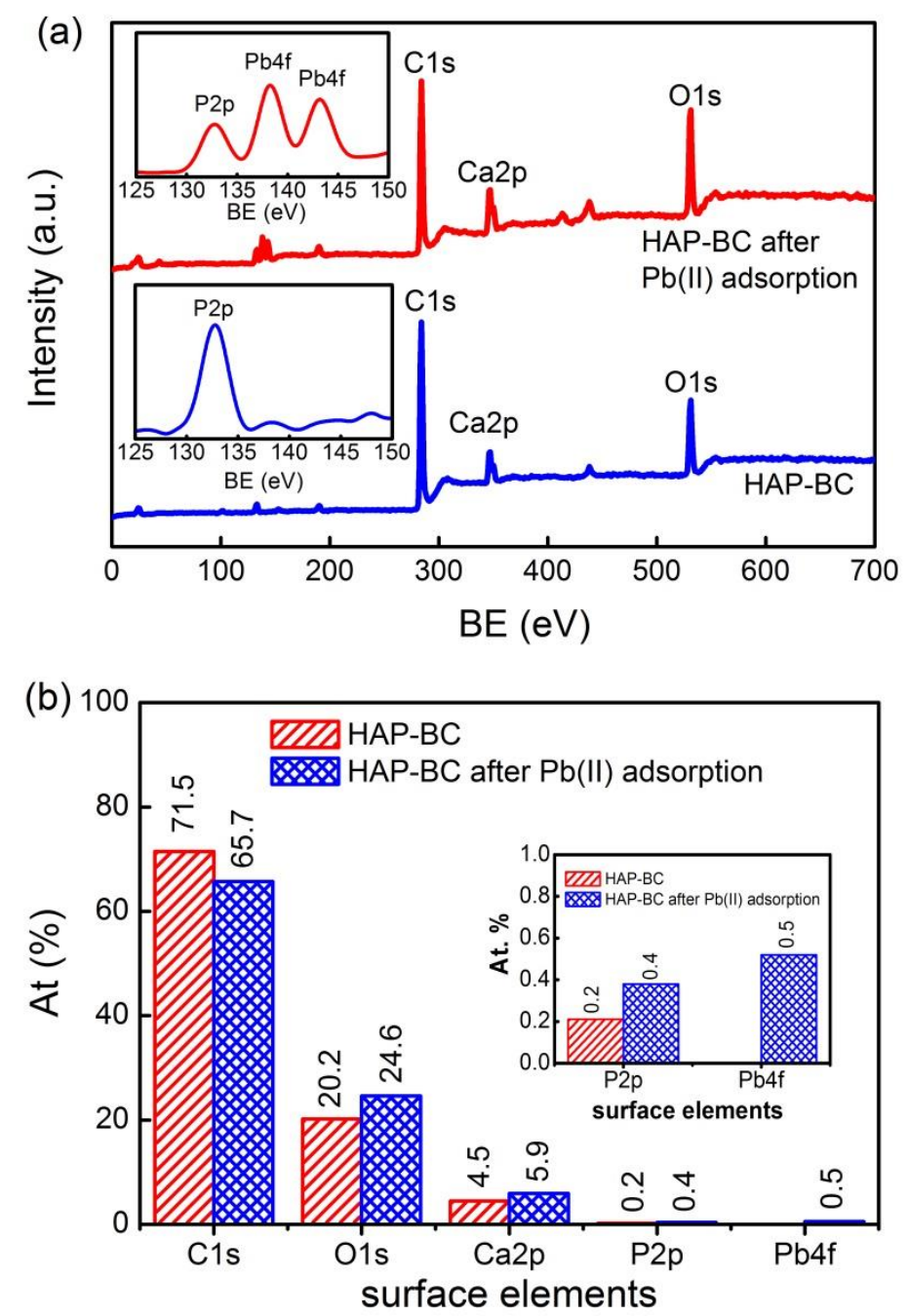

Fig. 7. XPS of the: (a) full spectrogram; and (b) Atomic concentration of the surface elements of the HAP-BC before and after $\mathrm{Pb}(\mathrm{II})$ adsorption

The XPS spectra of the O1s and C1s orbitals are shown in Figs. 8a, 8a', 8b, and 8b'. The high-resolution XPS C1s spectra are shown in Figs. 8a and 8a'. 

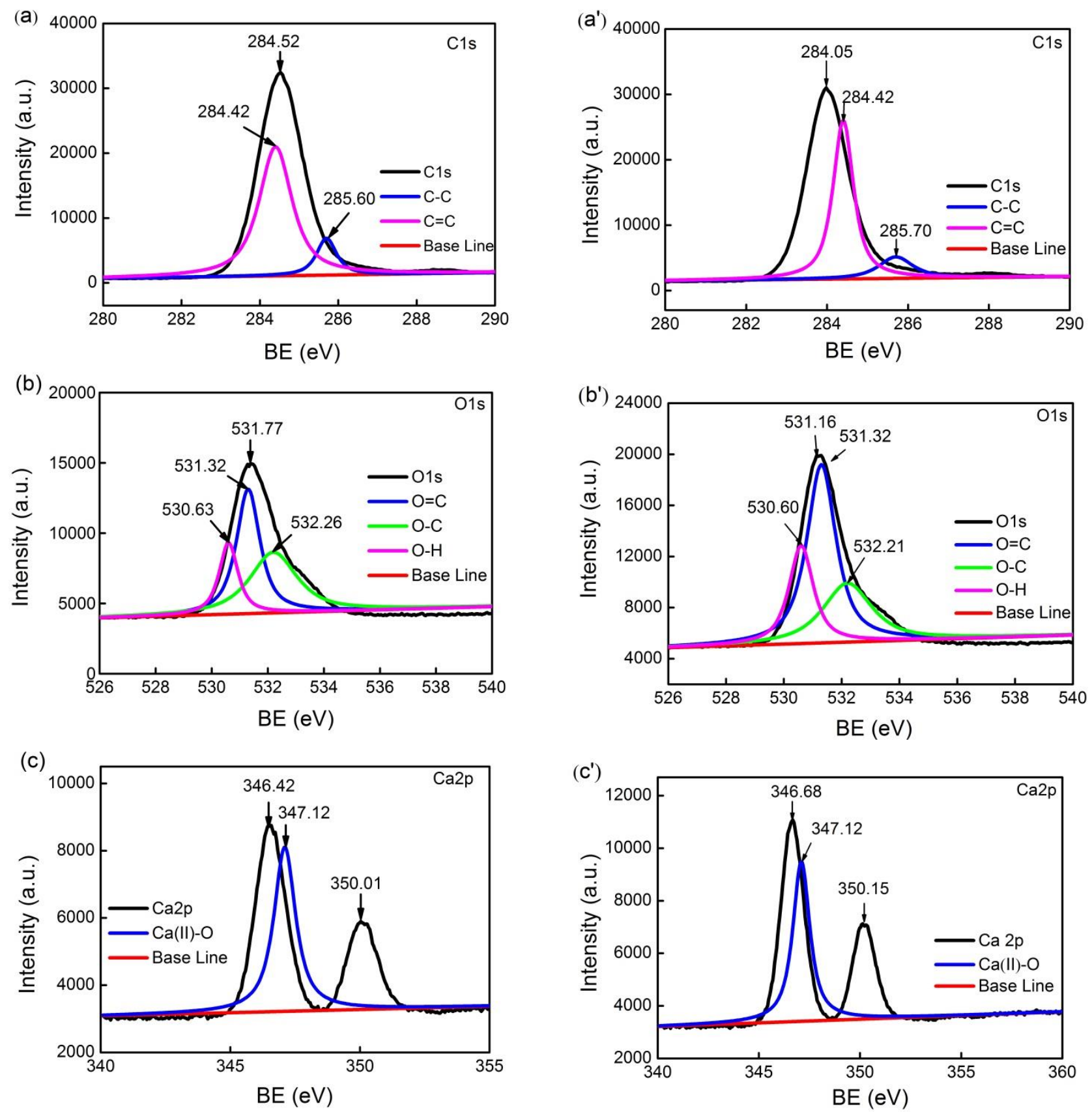

Fig. 8. XPS sub-peak fitted spectra of HAP-BC before and after $\mathrm{Pb}$ (II) adsorption: (a) C1s of HAPBC; (a') C1s of HAP-BC after Pb(II) adsorption; (b) O1s of HAP-BC; (b') O1s of HAP-BC after Pb(II) adsorption; (c) Ca2p of HAP-BC; and (c') Ca2p of HAP-BC after Pb(II) adsorption

The peak of typical graphitic carbon at 284.52 and $284.05 \mathrm{eV}$ represents the $\mathrm{C} 1 \mathrm{~s}$ binding energy of the HAP-BC before and after $\mathrm{Pb}(\mathrm{II})$ adsorption, respectively. The $\mathrm{C} 1 \mathrm{~s}$ peak was shifted by $0.47 \mathrm{eV}$, suggesting that the species of carbon is influenced by $\mathrm{Pb}(\mathrm{II})$; no shift in the XPS spectra of $\mathrm{C}-\mathrm{C}$ and $\mathrm{C}=\mathrm{C}$ suggested that carbon was not involved in the adsorption process. Figures $8 \mathrm{~b}$ and $8 \mathrm{~b}$ ' show that the primary O1s peak was shifted from 531.77 to $531.16 \mathrm{eV}$ after $\mathrm{Pb}(\mathrm{II})$ adsorption, i.e., the oxygen peak was shifted by $0.61 \mathrm{eV}$. This shift may be due to $\mathrm{Pb}_{5}\left(\mathrm{PO}_{4}\right)_{3}(\mathrm{OH})$ pellets beginning to form and cover the adsorbent surface of the HAP-BC. Results showed the presence of oxygen-containing functional 
groups on the surface of HAP-BC in the form of carbonyl oxygen, i.e., $-\mathrm{O}=\mathrm{C},(530.6 \mathrm{eV})$, hydroxyl, i.e., $-\mathrm{O}-\mathrm{H},(531.32 \mathrm{eV}$ ), and carboxyl oxygen, i.e., - $\mathrm{O}-\mathrm{C},(532.26 \mathrm{eV})$ (Zhang et al. 2010). The $\mathrm{Pb}$ (II) adsorption was accompanied by a change in oxygen binding, which provided evidence that the oxygen-containing functional groups on the surface of HAP$\mathrm{BC}$ took part in the $\mathrm{Pb}$ (II) adsorption process. The bonding energy of $\mathrm{Ca} 2 \mathrm{p}$ increased from 346.42 to $346.68 \mathrm{eV}$ after the $\mathrm{Pb}$ (II) adsorption by HAP-BC; these values were typical for $\mathrm{Ca}^{2+}$ in hydroxylapatite (as shown in Fig. 8c and 8c').

The change in bonding energy was illustrated by the electron transfer in the valence band, as well as the actual charge transfers, due to chemical reactions. Accordingly, by tracking the change in the core level peak position of the substrate, with and without the formation of surface complexes, it was possible to deduce the direction of the electron transfer during adsorption as well as to assess the relative acidity and basicity of the substrate and evaluate the adsorbate (Ding et al. 2000). The O1s binding energy and intensity shift were dependent on the content of different oxygen atoms, especially on the surface of HAP-BC. A simple formula connecting the O1s chemical shift and charge was constructed using the frontier molecular orbital theory as the theoretical framework, as shown in Eq. 8,

$$
Q_{0}=-4.372+\frac{\left[385.023-8.976 \times(545.509-O 1 s B E)^{1 / 2}\right.}{4.488}
$$

where $Q_{0}$ is the actual oxygen charge in the adsorbent (esu) and $\mathrm{O} 1 \mathrm{sBE}$ is the O1s binding energy determined via XPS (eV).

According to Eq. 8, the charge of the oxygen on the HAP-BC surface before and after $\mathrm{Pb}(\mathrm{II})$ adsorption were -0.84 and -0.80 esu, respectively (as shown in Table 5). This indicated the actual charge of oxygen was insignificantly changed, and $\mathrm{Pb}(\mathrm{II})$ adsorption by HAP-BC did not involve noticeable electron transfer between the HAP-BC surface and $\mathrm{Pb}$ (II) after the $\mathrm{Pb}$ (II) adsorption process. Since the actual transferred charge amount was 0.04 esu, which is less than 1 esu, the outer shared electronics of the oxygen atom on the surface the HAP-BC may be offset during the bond formation process (Ding et al. 2000). The oxygen from HAP-BC acts as a Lewis base, while various $\mathrm{Pb}$ (II) ions in the aqueous solution act as a Lewis acid (Ding et al. 2000).

Table 5. Oxygen (1s) Binding Energies, Charge Changes, and Electron Transfer Direction for the Hydroxylapatite Bagasse Biochar Composite (HAP-BC) Before and After $\mathrm{Pb}$ (II) Adsorption

\begin{tabular}{|c|c|c|c|}
\hline Compound & Binding Energy (eV) & Charges (esu) & Electron Transfer Direction \\
\hline HAP-BC & 530.63 & -0.84 & - \\
\hline After $\mathrm{Pb}(\mathrm{II})$ adsorption & 531.25 & -0.80 & Electron donor \\
\hline
\end{tabular}

The XPS spectra of the $\mathrm{Pb} 4 \mathrm{f}, \mathrm{Pb} 4 \mathrm{f}_{5 / 2}$, and $4 \mathrm{f}_{7 / 2}$ orbitals are shown in Fig. S5, which demonstrated that the $\mathrm{Pb} 4 \mathrm{f}$ peak was at $138.8 \mathrm{eV}$, the $\mathrm{Pb} 4 \mathrm{f}_{5 / 2}$ peak was at $138.9 \mathrm{eV}$, and the $\mathrm{Pb}_{4} \mathrm{f}_{7 / 2}$ peak was at $143.8 \mathrm{eV}$. The shift of the $\mathrm{Pb} 4 \mathrm{f}$ orbital spectra at a binding energy (BE) of $143.8 \mathrm{eV}$ after $\mathrm{Pb}$ (II) absorption clearly demonstrated that the oxygen-containing functional groups were involved in the adsorption reaction, and that hydroxylapatite played a significant role in $\mathrm{Pb}(\mathrm{II})$ adsorption. 


\section{Engineering Implications}

The mining wastewater was adsorbed by HAP-BC, which had initial concentrations of arsenic, lead, zinc, and cadmium in the mining wastewater of $0.39,0.26,3.55$, and 2.16 $\mathrm{mg} \cdot \mathrm{g}^{-1}$, respectively. At a $\mathrm{pH}$ of 9.0 , the removal percentage of arsenic, lead, zinc, and cadmium by HAP-BC were $88.83 \%, 100.00 \%, 99.89 \%$, and $99.68 \%$, respectively (as shown in Table 6). The removal of lead, cadmium, and zinc by HAP-BC was greater than the removal of arsenic at a $\mathrm{pH}$ of 5.0, 7.0, and 9.0. As such, HAP-BC can efficiently treat complex $\mathrm{Pb}(\mathrm{II})$-containing wastewater.

Table 6. Experimental Results of Adsorption of Mining Wastewater by Hydroxylapatite Bagasse Biochar Composite (HAP-BC)

\begin{tabular}{|c|c|c|c|c|c|c|c|c|}
\hline \multirow{2}{*}{$\mathrm{pH}$} & \multicolumn{4}{|c|}{ Removal (\%) } & \multicolumn{3}{c|}{ Residual Concentration $\left(\mathrm{mg} \cdot \mathrm{L}^{-1}\right)$} \\
\cline { 2 - 9 } & Arsenate & Lead & Zinc & Cadmium & Arsenate & Lead & Zinc & Cadmium \\
\hline 5.0 & 80.83 & 100.00 & 82.70 & 85.89 & 0.074 & - & 0.62 & 0.30 \\
\hline 7.0 & 85.28 & 100.00 & 92.26 & 98.93 & 0.057 & - & 0.28 & 0.02 \\
\hline 9.0 & 88.83 & 100.00 & 99.89 & 99.68 & 0.043 & - & 0.00 & 0.01 \\
\hline
\end{tabular}

Results show the benefits of HAP-BC as an adsorbent for the removal of $\mathrm{Pb}$ (II) in water. From the view of engineering process applications, the adsorbent has three major attributes. First, the HAP particles contribute to the considerable specific surface area of the HAP-BC, which provides abundant surface sites necessary for heavy metal ion adsorption.

Second, the bagasse support allows for the design of the metal removal processes to operate in a fixed bed mode, which can greatly reduce the post-metal treatment costs of particle separation. Finally, the $\mathrm{pH}$-dependent nature of the metal adsorption process permits easy regeneration of the saturated adsorbent. It is feasible to regenerate the HAP$\mathrm{BC}$ when it reaches maximum adsorption capacity.

In actuality, at a $\mathrm{pH}$ of less than 2 or greater than 9 , the $\mathrm{Pb}$ (II) ions are easy to desorb from the surface of HAP-BC. In addition, it was easy to recover the $\mathrm{Pb}$ (II) from regenerating solutions because the $\mathrm{Pb}(\mathrm{II})$ concentration was high in those solutions.

\section{Reusability}

Figure 9 shows the differences in $\mathrm{Pb}$ (II) removal to estimate the reusability of the SB-BC and HAP-BC after 4 adsorption/desorption cycles. As such, the SB-BC and HAP$\mathrm{BC}$ were washed with a $2.1 \% \mathrm{HCl}$ solution after the adsorption of $\mathrm{Pb}$ (II), oven-dried, and then recycled for $\mathrm{Pb}$ (II) removal. The results showed that there was difference in the $\mathrm{Pb}$ (II) removal percentage between SB-BC and HAP-BC after washing with acid. In first cycle, the $\mathrm{Pb}(\mathrm{II})$ removal percentage by $\mathrm{SB}-\mathrm{BC}$ and $\mathrm{HAP}-\mathrm{BC}$ were $57.21 \%$ and $95.67 \%$, respectively, while after the $4^{\text {th }}$ cycle it changed to $51.76 \%$ and $92.52 \%$, respectively. The difference in the $\mathrm{Pb}(\mathrm{II})$ removal percentage was $5.45 \%$ and $3.15 \%$, respectively. As such, $\mathrm{HAP}-\mathrm{BC}$ had greater reusability than $\mathrm{SB}-\mathrm{BC}$ in terms of removing $\mathrm{Pb}$ (II) from contaminated water. 


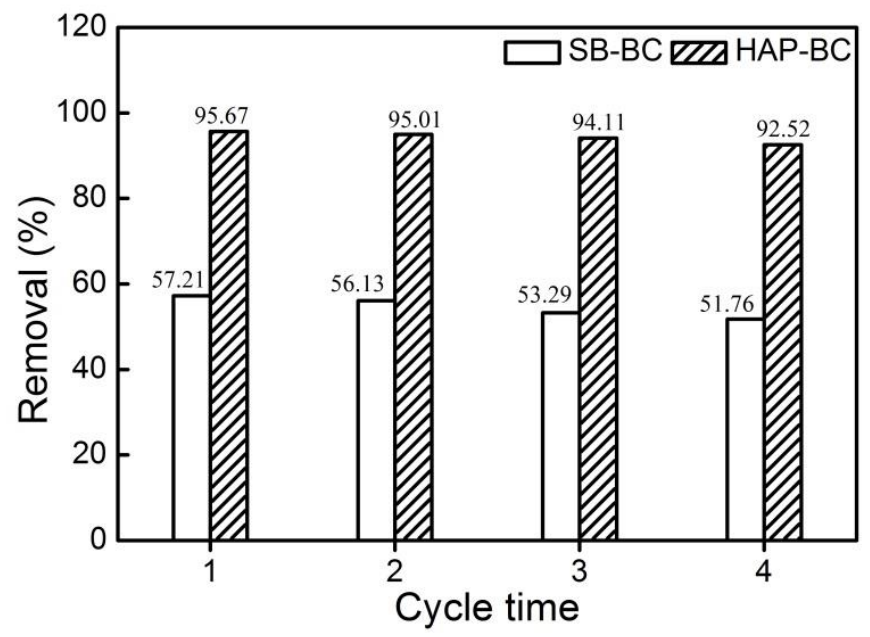

Fig. 9. The reusability of $\mathrm{SB}-\mathrm{BC}$ and $\mathrm{HAP}-\mathrm{BC}$ for the removal of $\mathrm{Pb}(\mathrm{II})$

\section{CONCLUSIONS}

1. From the results obtained, the optimum $\mathrm{pH}$ for $\mathrm{Pb}(\mathrm{II})$ adsorption by HAP-BC was between 4.0 and 7.0. The maximum adsorption capacity of $\mathrm{Pb}$ (II) by HAP-BC, as calculated by the Langmuir isotherm, was $210 \mathrm{mg} \mathrm{g}^{-1}$ at $25^{\circ} \mathrm{C}$.

2. The removal mechanism of $\mathrm{Pb}$ (II) by HAP-BC in solution was primarily by surface diffusion, electrostatic attraction, surface complexation, ion exchange, and a dissolving coprecipitation reaction.

3. The oxygen-containing functional groups, i.e., $\mathrm{O}=\mathrm{C}, \mathrm{O}-\mathrm{C}$, and $\mathrm{O}-\mathrm{H}$, of HAP-BC were involved in adsorbing $\mathrm{Pb}(\mathrm{II})$. The shift of the $\mathrm{Pb} 4 \mathrm{f}$ orbital spectra at a binding energy (BE) of $143.84 \mathrm{eV}$ after the $\mathrm{Pb}(\mathrm{II})$ absorption process by HAP-BC demonstrated that the surface oxygen-containing functional groups were involved in the adsorption reaction.

4. The HAP-BC was used to treat complex water bodies containing arsenic, zinc, and cadmium, and its removal rate of lead was as much as $100 \%$, which suggests it is a promising environmentally friendly functional material and can be used in environmental pollution control.

\section{ACKNOWLEDGEMENTS}

This research was financially assisted by the National Natural Science Foundation of China (No. 21367010 and No. 51638006) and the Guangxi Mid-Youth Capability Project (No. 2020KY06038). 


\section{REFERENCE CITED}

Argun, M. E., Dursun, S., Ozdemir, C., and Karatas, M. (2007). "Heavy metal adsorption by modified oak sawdust: Thermodynamics and kinetics," Journal of Hazardous Materials 141(1), 77-85. DOI: 10.1016/j.jhazmat.2006.06.095

Bardestani, R., Roy, C., and Kalioguine, S. (2019). "The effect of biochar mild air oxidation on the optimization of lead(II) adsorption from wastewater," Journal of Environmental Management 240, 404-420. DOI: 10.1016/j.jenvman.2019.03.110

Chand, P., and Pakade, Y. B. (2015). "Synthesis and characterization of hydroxyapatite nanoparticles impregnated on apple pomace to enhanced adsorption of $\mathrm{Pb}(\mathrm{II}), \mathrm{Cd}(\mathrm{II})$, and $\mathrm{Ni}(\mathrm{II})$ ions from aqueous solution," Environmental Science and Pollution Research 22(14), 10919-10929. DOI: 10.1007/s11356-015-4276-2

Corami, A., Mignardi, S., and Ferrini, V. (2008). "Cadmium removal from single- and multi-metal $(\mathrm{Cd}+\mathrm{Pb}+\mathrm{Zn}+\mathrm{Cu})$ solutions by sorption on hydroxyapatite," Journal of Colloid and Interface Science 317(2), 402-408. DOI: 10.1016/j.jcis.2007.09.075

Corapcioglu, M. O., and Huang, C. P. (1987). "The surface acidity and characterization of some commercial activated carbons," Carbon 25(4), 569-578. DOI: 10.1016/00086223(87)90200-4

Crini, G. (2005). "Recent developments in polysaccharide-based materials used as adsorbents in wastewater treatment," Progress in Polymer Science 30(1), 38-70. DOI: 10.1016/j.progpolymsci.2004.11.002

Crini, G. (2008). "Kinetic and equilibrium studies on the removal of cationic dyes from aqueous solution by adsorption onto a cyclodextrin polymer," Dyes and Pigments 77(2), 415-426. DOI: 10.1016/j.dyepig.2007.07.001

De, J. B. H. W. S., and Ellerbroek, D. (1994). "Low-temperature structure of lithium nesosilicate, $\mathrm{Li}_{4} \mathrm{SiO}_{4}$, and its $\mathrm{Li}_{1 \text { s }}$ and $\mathrm{O}_{1 \mathrm{~s}} \mathrm{X}$-ray photoelectron spectrum," Acta Crystallographica 50(5), 511-518. DOI: 10.1107/S0108768194002375

Ding, M., Jong, B. H. W. S. d., Roosendaal, S. J., and Vredenberg, A. (2000). "XPS studies on the electronic structure of bonding between solid and solutes: adsorption of arsenate, chromate, phosphate, $\mathrm{Pb}^{2+}$, and $\mathrm{Zn}^{2+}$ ions on amorphous black ferric oxyhydroxide," Geochimica et Cosmochimica Acta 64(7), 1209-1219. DOI: 10.1016/S0016-7037(99)00386-5

Elouear, Z., Bouzid, J., Boujelben, N., Feki, M., Jamoussi, F., and Montiel, A. (2008). "Heavy metal removal from aqueous solutions by activated phosphate rock," Journal of Hazardous Materials 156(1), 412-420. DOI: 10.1016/j.jhazmat.2007.12.036

Feng, N., Guo, X., and Liang, S. (2009). "Adsorption study of copper (II) by chemically modified orange peel," Journal of Hazardous Materials 164(2), 1286-1292. DOI: 10.1016/j.jhazmat.2008.09.096

Fu, C.-L., Zhang, H.-L., Xia, M.-Z., Lei, W., and Wang, F.-Y. (2020). "The single/coadsorption characteristics and microscopic adsorption mechanism of biocharmontmorillonite composite adsorbent for pharmaceutical emerging organic contaminant atenolol and lead ions," Ecotoxicology and Environmental Safety 187, article no. 109763. DOI: 10.1016/j.ecoenv.2019.109763

Gao, L., Li, Z.-H., Yi, W.-M., Li, Y.-F., Zhang, P., Zhang, A.-D., and Wang, L.-H. (2021). "Impacts of pyrolysis temperature on lead adsorption by cotton stalk-derived biochar and related mechanisms," Journal of Environmental Chemical Engineering 9, article no. 105602. 10.1016/j.jece.2021.105602

Gupta, N., Kushwaha, A. K., and Chattopadhyaya, M. C. (2012). “Adsorptive removal of 
$\mathrm{Pb}^{2+}, \mathrm{Co}^{2+}$ and $\mathrm{Ni}^{2+}$ by hydroxyapatite/chitosan composite from aqueous solution," Journal of the Taiwan Institute of Chemical Engineers 43(1), 125-131. DOI: 10.1016/j.jtice.2011.07.009

Jayakodiarachchi, N., and Jayaweera, C. D. (2015). "A study of the removal characteristics of $\mathrm{Cu}$ (ii) ions from aqueous solutions by a low-cost adsorbent," in Proceedings of the 20 ${ }^{\text {th }}$ International Forestry and Environment Symposium, 16-17 October, Waikkal, Sri Lanka.

Kloss, S., Zehetner, F., Dellantonio, A., Hamid, R., Ottner, F., Liedtke, V., Schwanninger, M., Gerzabek, M. H., and Soja, G. (2012). "Characterization of slow pyrolysis biochars: Effects of feedstocks and pyrolysis temperature on biochar properties," Journal of Environmental Quality 41(4), 990-1000. DOI: 10.2134/jeq2011.0070

Kwak, J.-H., Islam, M. S., Wang, S.-Y., Messele, S. A., Naeth, M. A., El-Din, M. G., and Chang, S. X. (2019). "Biochar properties and lead(II) adsorption capacity depend on feedstock type, pyrolysis temyanperature, and steam activation," Chemosphere 231, 393-404. DOI: 10.1016/j.chemosphere.2019.05.128

Lee, S., Dyer, J. A., Sparks, D. L., Scrivner, N. C., and Elzinga, E. J. (2006). “A multiscale assessment of $\mathrm{Pb}(\mathrm{II})$ sorption on dolomite," Journal of Colloid and Interface Science 298(1), 20-30. DOI: 10.1016/j.jcis.2005.12.022

Liang, M., Wang, D., Zhu, Y., Zhu, Z., Li, Y., and Huang, C. P. (2018). "Nano-hematite bagasse composite (n-HBC) for the removal of $\mathrm{Pb}(\mathrm{II})$ from dilute aqueous solutions," Journal of Water Process Engineering 21, 69-76. DOI: 10.1016/j.jwpe.2017.11.014

Liu, P., Liu, W.J., Jiang, H., Chen, J.J., Li, W.W., and Yu, H.Q. (2012). "Modification of bio-char derived from fast pyrolysis of biomass and its application in removal of tetracycline from aqueous solution," Bioresource Technology 121, 235-240. DOI: 10.1016/j.biortech.2012.06.085.

Meski, S., Ziani, S., and Khireddine, H. (2010). "Removal of lead ions by hydroxyapatite prepared from the egg shell," Journal of Chemical \& Engineering Data 55(9), 39233928. DOI: $10.1021 / \mathrm{je} 901070 \mathrm{e}$

Mondal, P., Balomajumder, C., and Mohanty, B. (2007). "A laboratory study for the treatment of arsenic, iron, and manganese bearing ground water using $\mathrm{Fe}^{3+}$ impregnated activated carbon: Effects of shaking time, $\mathrm{pH}$ and temperature," Journal of Hazardous Materials 144(1), 420-426. DOI: 10.1016/j.jhazmat.2006.10.078

Naushad, M. (2014). "Surfactant assisted nano-composite cation exchanger: Development, characterization and applications for the removal of toxic $\mathrm{Pb}^{2+}$ from aqueous medium," Chemical Engineering Journal 235, 100-108. DOI: 10.1016/j.cej.2013.09.013

Naushad, M., Alothman, Z. A., Awual, M. R., and Mezbaul Alam, M. (2015). "Adsorption kinetics, isotherms, and thermodynamic studies for the adsorption of $\mathrm{Pb}^{2+}$ and $\mathrm{Hg}^{2+}$ metal ions from aqueous medium using Ti(IV) iodovanadate cation exchanger," Ionics 21, 2237-2245. DOI: 10.1007/s11581-015-1401-7

Naushad, M., Mittal, A., Rathore, M., and Gupta, V. (2014). "Ion-exchange kinetic studies for $\mathrm{Cd}(\mathrm{II}), \mathrm{Co}(\mathrm{II}), \mathrm{Cu}(\mathrm{II})$, and $\mathrm{Pb}(\mathrm{II})$ metal ions over a composite cation exchanger," Desalination and Water Treatment 1-8. DOI: 10.1080/19443994.2014.904823

Nzediegwu, C., Naeth, M. A., and Chang, S. X. (2021). "Lead(II) adsorption on microwave-pyrolyzed biochars and hydrochars depends on feedstock type and production temperature," Journal of Hazardous Materials 412, article no. 125255.

DOI: 10.1016/j.jhazmat.2021.125255

Saber-Samandari, S., Saber-Samandari, S., Nezafati, N., and Yahya, K. (2014). "Efficient 
removal of lead (II) ions and methylene blue from aqueous solution using chitosan/Fe-hydroxyapatite nanocomposite beads," Journal of Environmental Management 146, 481-490. DOI: 10.1016/j.jenvman.2014.08.010

Satyanarayana, K. G., Guimarães, J. L., and Wypych, F. (2007). "Studies on lignocellulosic fibers of Brazil. Part I: Source, production, morphology, properties and applications," Composites Part A: Applied Science and Manufacturing 38(7), 1694-1709. DOI: 10.1016/j.compositesa.2007.02.006

Sreejalekshmi, K. G., Krishnan, K. A., and Anirudhan, T. S. (2009). “Adsorption of $\mathrm{Pb}(\mathrm{II})$ and $\mathrm{Pb}$ (II)-citric acid on sawdust activated carbon: Kinetic and equilibrium isotherm studies". Journal of Hazardous Materials 161(2), 1506-1513. DOI: 10.1016/j.jhazmat.2008.05.002.

Srinivasan, M., Ferraris, C., and White, T. (2006). "Cadmium and lead ion capture with three dimensionally ordered macroporous hydroxyapatite," Environmental Science \& Technology 40(22), 7054-7059. DOI: 10.1021/es060972s

Wang, Y., Wang, X., Wang, X., Liu, M., Yang, L., Wu, Z., Xia, S., and Zhao, J. (2012). "Adsorption of $\mathrm{Pb}$ (II) in aqueous solutions by bamboo charcoal modified with $\mathrm{KMnO}_{4}$ via microwave irradiation," Colloids and Surfaces A: Physicochemical and Engineering Aspects 414, 1-8. DOI: 10.1016/j.colsurfa.2012.08.007

$\mathrm{Xu}$, D., Tan, X., Chen, C., and Wang, X. (2008). "Removal of Pb(II) from aqueous solution by oxidized multiwalled carbon nanotubes," Journal of Hazardous Materials 154(1), 407-416. DOI: 10.1016/j.jhazmat.2007.10.059

Xu, Y.-G., Bai, T.-X., Li, Q., Yang, H.-T., Yan, Y.-B., Sarkar, B., Lam, S. S., and Bolan, N. (2021). "Influence of pyrolysis temperature on the characteristics and lead(II) adsorption capacity of phosphorus-engineered poplar sawdust biochar," Journal of Analytical and Applied Pyrolysis 154, article no. 105010. DOI: 10.1016/j.jaap.2020.105010

Yan, Y., Dong, X., Sun, X., Sun, X., Li, J., Shen, J., Han, W., Liu, X., and Wang, L. (2014). "Conversion of waste FGD gypsum into hydroxyapatite for removal of $\mathrm{Pb}^{2+}$ and $\mathrm{Cd}^{2+}$ from wastewater," Journal of Colloid and Interface Science 429, 68-76. DOI: $10.1016 /$ j.jcis.2014.05.010

Yan, L.-L., Liang, M.-N., Wang, D.-Q., Zhang, L.-H., Zhu, Z.-Q., and Huang, D.-L. (2019). "Dynamic adsorption of As(V) by hydroxyapatite/bagasse biomass carbon composite adsorbent," IOP Conf. Series: Materials Science and Engineering 490, article no. 032037. DOI:10.1088/1757-899X/490/3/032037.

Yan, Y.-B., Sarkar, B., Zhou, L., Zhang, L., Li, Q., Yang, J.-J., and Bolan, N. (2020). "Phosphorus-rich biochar produced through bean-worm skin waste pyrolysis enhances the adsorption of aqueous lead," Environmental Pollution 266, article no. 115177. DOI: $10.1016 /$ j.envpol.2020.115177

Yang, W.-C., Wang, Z.-W., Song, S.-A., Han, J.-B., Chen, H., Wang, X.-M., Sun, R.-J., and Cheng, J.-Y. (2019). "Adsorption of copper(II) and lead(II) from seawater using hydrothermal biochar derived from Enteromorpha," Marine Pollution Bulletin 149, article no. 110586. DOI: /10.1016/j.marpolbul.2019.110586

Zhang, J.-J., Saho, J.-G., Jin, Q.-Z., Zhang, X., Yang, H.-P., Chen, Y.-Q., Zhang, S.-H., and Chen, H.-P. (2020). "Effect of deashing on activation process and lead adsorption capacities of sludge-based biochar," Science of The Total Environment 716, article no. 137016. DOI: 10.1016/j.scitotenv.2020.137016

Zhang, S., Li, X., and Chen, J. P. (2010). "An XPS study for mechanisms of arsenate adsorption onto a magnetite-doped activated carbon fiber," Journal of Colloid and 
Interface Science 343(1), 232-238. DOI: 10.1016/j.jcis.2009.11.001

Zhang, Y., Cao, B., Zhao, L.-L., Sun, L.-L., Gao, Y., Li, J.-J., and Yang, F. (2018).

"Biochar-supported reduced graphene oxide composite for adsorption and coadsorption of atrazine and lead ions," Applied Surface Science, 427: 147-155. DOI: 10.1016/j.apsusc.2017.07.237

Article submitted: July 2, 2021; Peer review completed: October 4, 2021; Revised version received: December 21, 2021; Accepted: December 22, 2021; Published: January $5,2022$.

DOI: 10.15376/biores.17.1.1205-1231 


\section{APPENDIX}

\section{Supplementary}

\section{Preparation of HAP-BC and BC}

Bagasse was washed with water and dried in an oven at $80{ }^{\circ} \mathrm{C}$. Dried bagasse samples were sieved by the $0.84 \mathrm{~mm}$ mesh sieve, collected, and stored in a desiccator.

The $250 \mathrm{~mL}$ of $0.2 \mathrm{~mol} \mathrm{~L}^{-1} \mathrm{Ca}\left(\mathrm{CH}_{3} \mathrm{COO}\right)_{2}$ and $250 \mathrm{~mL}$ of $4.4 \mathrm{~mol} \mathrm{~L}^{-1} \mathrm{CH}_{3} \mathrm{COONH}_{4}$ were mixed into the $2000 \mathrm{~mL}$ beaker. A total of $50 \mathrm{~g}$ dried bagasse was added to the beaker and evenly mixed until the suspension was formed. The suspension was stirred for $10 \mathrm{~min}$, ultrasonically shaken for $30 \mathrm{~min}$, and incubated at $25{ }^{\circ} \mathrm{C}$ for $24 \mathrm{~h}$. The $500 \mathrm{~mL}$ of $0.06 \mathrm{~mol}$ $\mathrm{L}^{-1} \mathrm{NH}_{4} \mathrm{H}_{2} \mathrm{PO}_{4}$ was added under rapid stirring, followed by slow addition of $10 \%(\mathrm{~V} / \mathrm{V})$ $\mathrm{NH}_{3} \cdot \mathrm{H}_{2} \mathrm{O}$ to adjust the $\mathrm{pH}$ to 7.5 and continued stirring for $30 \mathrm{~min}$ at $25^{\circ} \mathrm{C}$. The beaker was covered with a watch glass and placed in a constant temperature water bath for reaction to reach equilibrium for $48 \mathrm{~h}$ at $100{ }^{\circ} \mathrm{C}$. The suspension was filtered to collect the solid precipitate. The solid precipitate was washed by ultrapure water and ethanol and dried in an oven at $70{ }^{\circ} \mathrm{C}$ for $16 \mathrm{~h}$. Finally, the HAP-BC was carbonized in a muffle furnace at 500 ${ }^{\circ} \mathrm{C}$ for $4 \mathrm{~h}$. The HAP-BC was sieved to $0.5 \sim 1 \mathrm{~mm}$ size fraction.

To prepare bagasse biochar, dried sugar bagasse was carbonized in a muffle furnace at $500{ }^{\circ} \mathrm{C}$ for $4 \mathrm{~h}$ in the absence of air. The bagasse biochar was sieved to 0.5 to $1 \mathrm{~mm}$ size fraction.

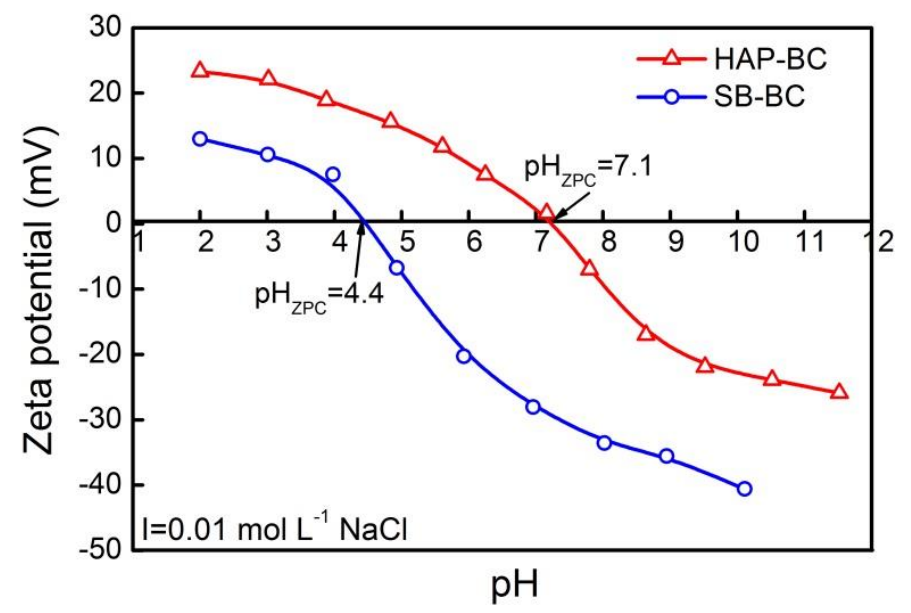

Fig. S1. Zeta potential of HAP-BC as function of $\mathrm{pH}$ in $0.01 \mathrm{~mol} \mathrm{~L}^{-1} \mathrm{NaCl}$ electrolyte solution

\section{Adsorption Isotherm-Freundlich isotherm}

The data were fit using Freundlich adsorption models according to Eq. S1,

$$
\ln q_{e}=\ln K_{F}+\left(\frac{1}{n}\right) \ln C_{e}
$$

where, $q_{e}$ is the amount of $\mathrm{Pb}(\mathrm{II})$ absorbed $\left(\mathrm{mg} \mathrm{g}^{-1}\right)$ at equilibrium state; $C_{e}$ is the equilibrium concentration of $\mathrm{Pb}(\mathrm{II})$ in solution $\left(\mathrm{mg} \mathrm{L}^{-1}\right) ; K_{F}\left(\mathrm{~L} \mathrm{~g}^{-1}\right)$ is the Freundlich 
constant, which is a rough indicator of the adsorption capacity, and $1 / n$ is the adsorption strength.

The values of $n$ and $K_{F}$ were calculated from the slope of plots and intercept (Table $\mathrm{S} 1)$. The coefficients of determination $\left(\mathrm{R}^{2}\right)$ were found to be $0.993,0.996$, and 0.997 for the adsorption at 25,35 , and $45^{\circ} \mathrm{C}$, respectively. $1 / n$ is the heterogeneity factor used as a measure of the deviation from linearity of the adsorption. $1 / n$ values were calculated from the slope of plots to be $0.438,0.443$, and 0.340 for the adsorption at 25,35 , and $45^{\circ} \mathrm{C}$, respectively.

Table S1. Freundlich Isotherm Parameters for the $\mathrm{Pb}$ (II) Adsorption on HAP-BC at Different Temperature

\begin{tabular}{|c|c|c|c|}
\hline \multirow{2}{*}{ Temperature $\left({ }^{\circ} \mathrm{C}\right)$} & \multicolumn{3}{|c|}{ Freundlich } \\
\cline { 2 - 4 } & $K_{\mathrm{F}}\left(\mathrm{L} \mathrm{g}^{-1}\right)$ & $1 / n$ & $\mathrm{R}^{2}$ \\
\hline 25 & 25.68 & 0.438 & 0.993 \\
\hline 35 & 28.11 & 0.443 & 0.996 \\
\hline 45 & 35.91 & 0.340 & 0.997 \\
\hline
\end{tabular}

\section{Adsorption Kinetics}

The results of kinetic model fitting for HAP-BC adsorption of $\mathrm{Pb}(\mathrm{II})$ are shown in Fig. S2.The fitting parameters of the four models are listed in Table S2.

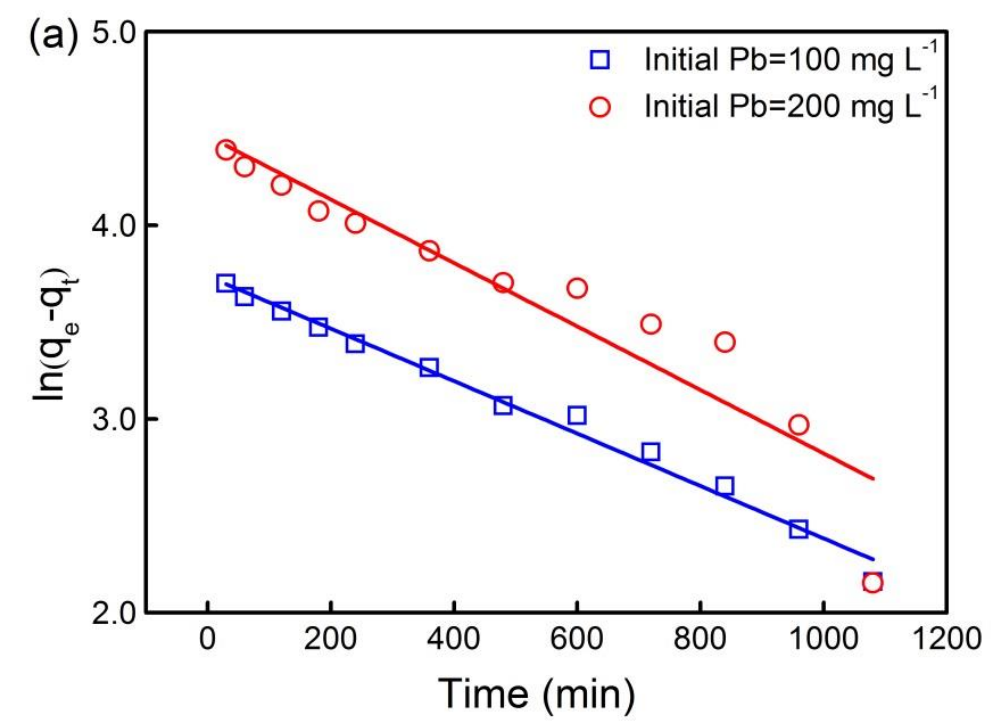



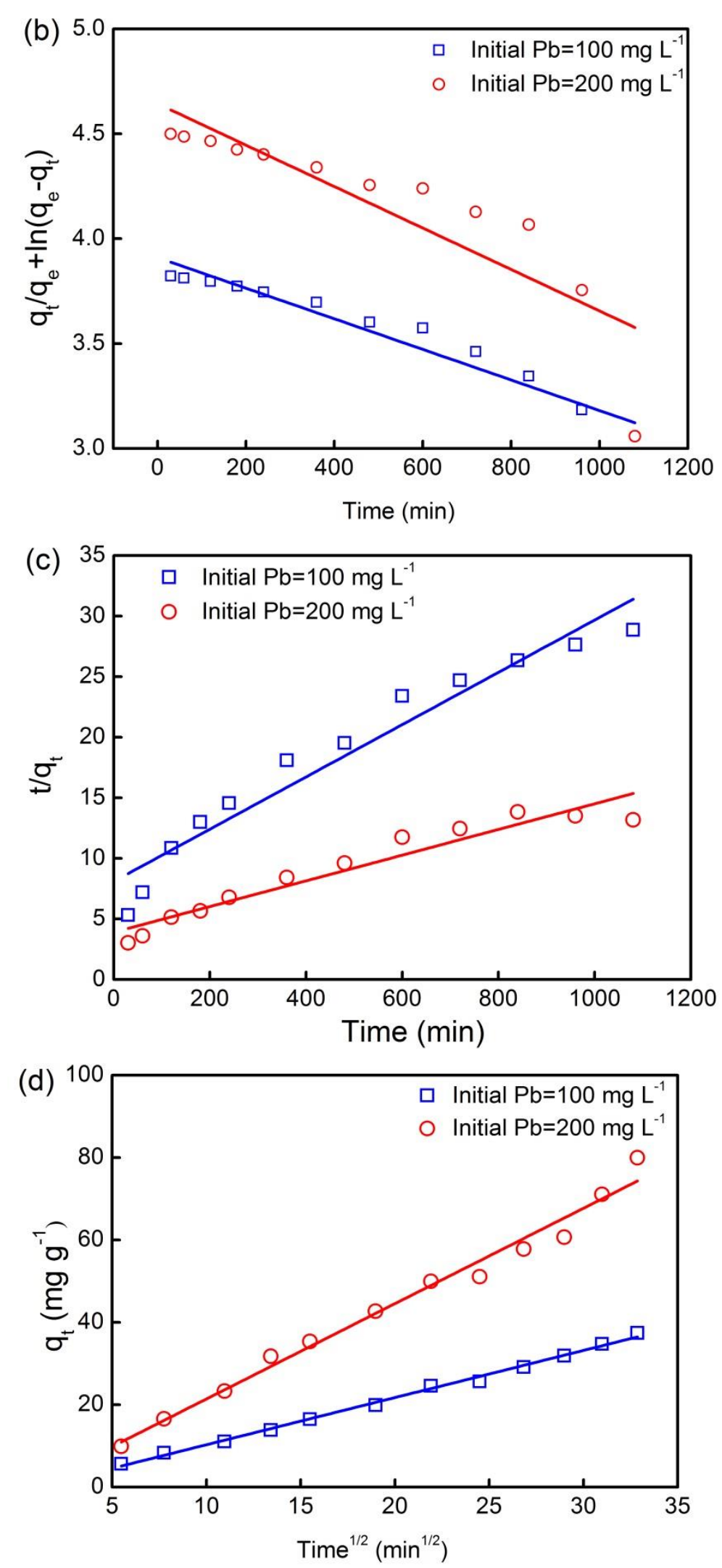

Fig. S2. Kinetics for $\mathrm{Pb}(\mathrm{II})$ adsorption onto HAP-BC(a, Pseudo-first-order kinetic model; b, Modified pseudo-first-order kinetic model; c, Pseudo-second-order kinetic model; d, Intra-particle diffusion kinetic model) 
Table S2. Parameters of Kinetic for $\mathrm{Pb}$ (II) Sorption onto HAP-BC

\begin{tabular}{|c|c|c|c|c|c|}
\hline \multicolumn{6}{|c|}{ Pseudo-first-order kinetic constant } \\
\hline Initial $\mathrm{Pb}(\mathrm{II})\left(\mathrm{mg} \mathrm{L}^{-1}\right)$ & \multicolumn{2}{|l|}{$K_{1}\left(\min ^{-1}\right)$} & \multicolumn{2}{|c|}{$q_{e}\left(\mathrm{mg} \mathrm{g}^{-1}\right)$} & $R^{2}$ \\
\hline 100.0 & \multicolumn{2}{|l|}{0.0015} & \multicolumn{2}{|l|}{42.0} & 0.979 \\
\hline 200.0 & \multicolumn{2}{|l|}{0.0016} & \multicolumn{2}{|l|}{86.6} & 0.877 \\
\hline \multicolumn{6}{|c|}{ Modified pseudo-first-order kinetic constant } \\
\hline Initial $\mathrm{Pb}(\mathrm{II})\left(\mathrm{mg} \mathrm{L}^{-1}\right)$ & \multicolumn{2}{|l|}{$K_{1}\left(\min ^{-1}\right)$} & \multicolumn{2}{|c|}{$q_{e}\left(\mathrm{mg} \mathrm{g}^{-1}\right)$} & $R^{2}$ \\
\hline 100.0 & \multicolumn{2}{|l|}{0.00073} & \multicolumn{2}{|l|}{22.2} & 0.928 \\
\hline 200.0 & \multicolumn{2}{|l|}{0.00099} & \multicolumn{2}{|l|}{103.9} & 0.737 \\
\hline \multicolumn{6}{|c|}{ Pseudo-second-order kinetic constant } \\
\hline Initial $\mathrm{Pb}(\mathrm{II})\left(\mathrm{mg} \mathrm{L}^{-1}\right)$ & $K_{2}\left(\mathrm{~g} \mathrm{mg}^{-1} \mathrm{~min}^{-1}\right)$ & \multicolumn{2}{|l|}{$q_{e}\left(\mathrm{mg} \mathrm{g}^{-1}\right)$} & $\mathrm{h}\left(\mathrm{g} \mathrm{mg}^{-1} \mathrm{~min}^{-1}\right)$ & $\overline{R^{2}}$ \\
\hline 100.0 & 0.417 & \multicolumn{2}{|l|}{46.5} & 0.110 & 0.939 \\
\hline 200.0 & 0.011 & \multicolumn{2}{|l|}{94.3} & 0.256 & 0.954 \\
\hline \multicolumn{6}{|c|}{ Intra-particle diffusion kinetic constant } \\
\hline Initial $\mathrm{Pb}(\mathrm{II})\left(\mathrm{mg} \mathrm{L}^{-1}\right)$ & \multicolumn{3}{|l|}{$K_{d}\left(\mathrm{~g} \mathrm{mg}^{-1} \mathrm{~min}^{-1 / 2}\right)$} & & $R^{2}$ \\
\hline 100.0 & \multicolumn{3}{|l|}{1.14} & & 0.996 \\
\hline 200.0 & \multicolumn{3}{|l|}{2.31} & & 0.982 \\
\hline
\end{tabular}

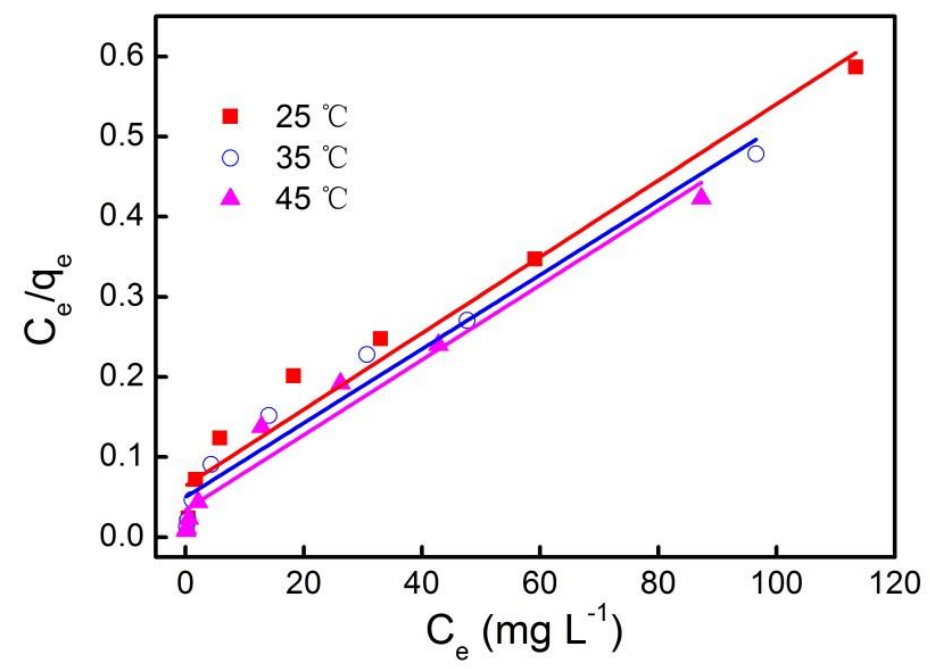

Fig. S3. Plot of linearized Langmuir adsorption isotherm 


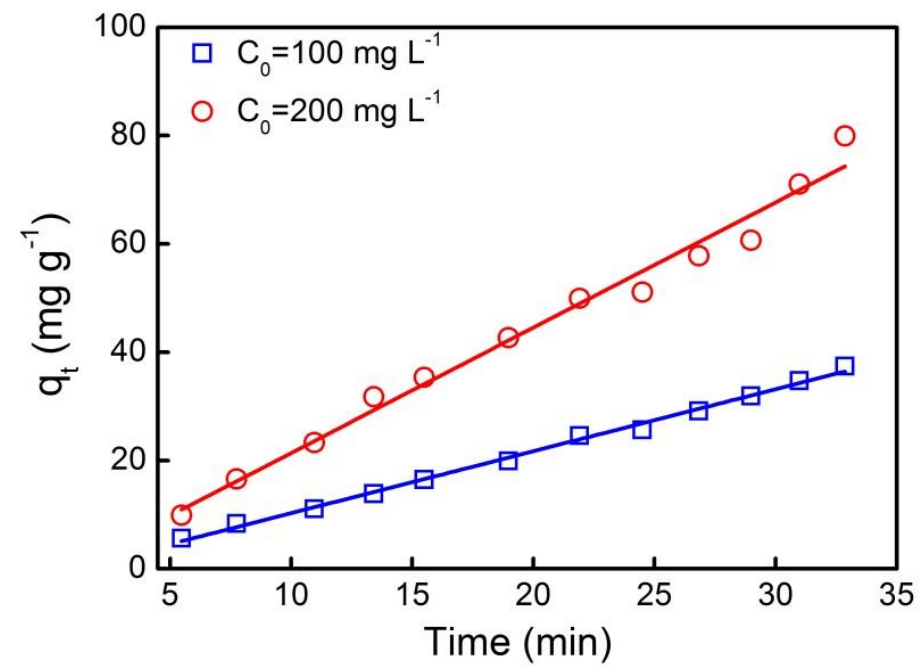

Fig. S4. Kinetics for $\mathrm{Pb}(\mathrm{II})$ adsorption onto HAP-BC intra-particle diffusion kinetic model

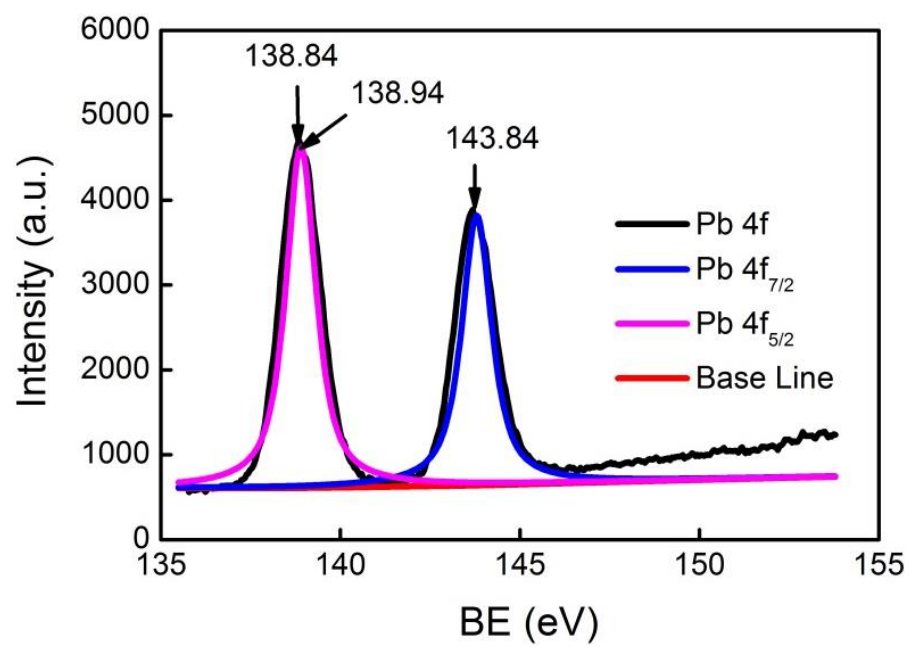

Fig. S5. Sub-peak fitted spectra of $\mathrm{Pb} 4 \mathrm{f}$ of $\mathrm{HAP}-\mathrm{BC}$ after $\mathrm{Pb}(\mathrm{II})$ adsorption

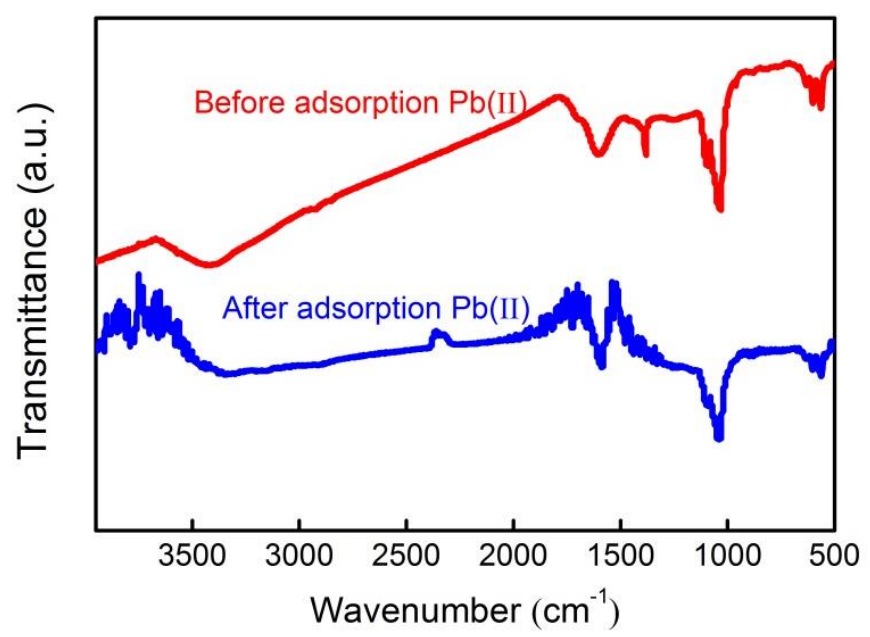

Fig. S6. FT-IR spectrogram of the HAP-BC before and after $\mathrm{Pb}(\mathrm{II})$ adsorption 

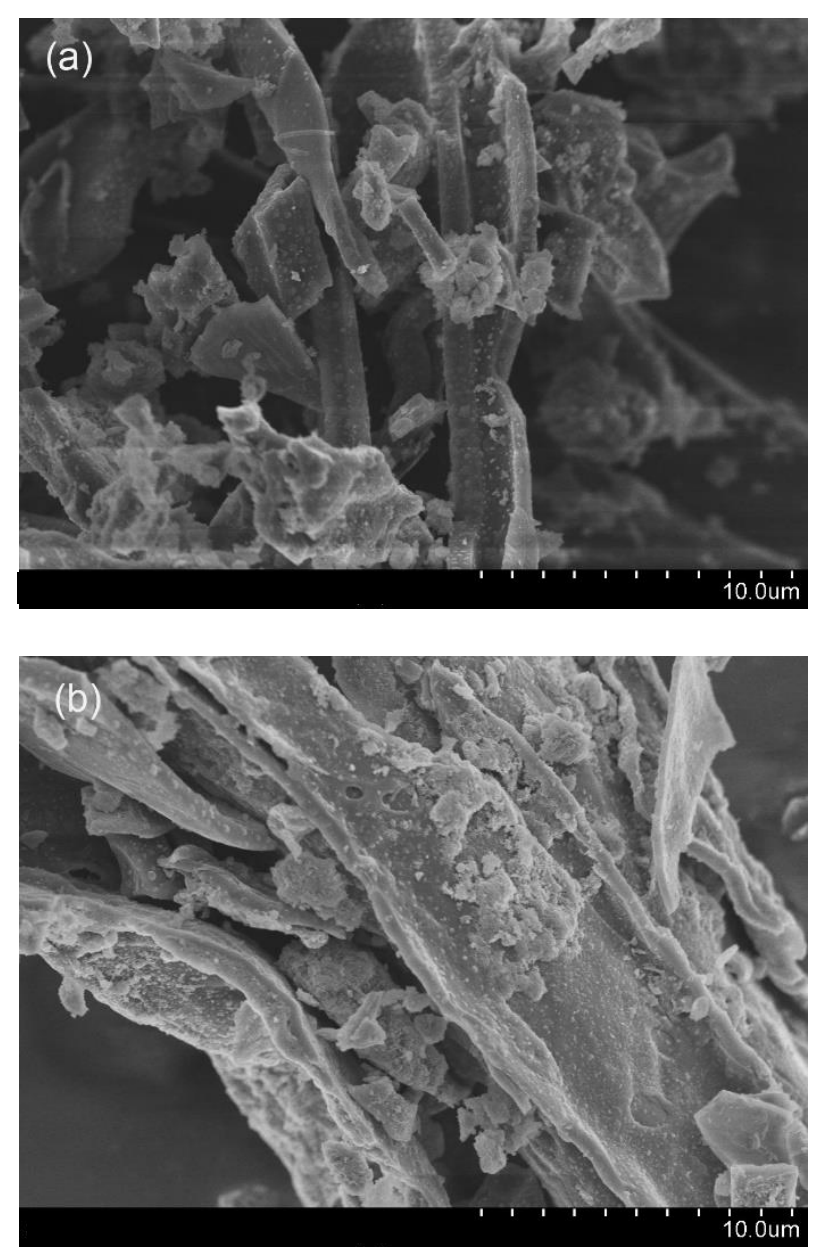

Fig. S7. SEM micrograph of HAP-BC before and after Pb(II) adsorption (a, HAP-BC; b, HAP-BC after $\mathrm{Pb}(\mathrm{II})$ adsorption)

Table S3. Mass (\%) and Atomic (\%) Surface Amounts on the HAP-BC Before and After $\mathrm{Pb}$ (II) Adsorption

\begin{tabular}{|c|c|c|c|c|c|}
\hline \multicolumn{3}{|c|}{ Before adsorption $\mathrm{Pb}(\mathrm{II})$} & \multicolumn{3}{c|}{ After adsorption $\mathrm{Pb}(\mathrm{II})$} \\
\hline Element & Mass(\%) & Atom(\%) & Element & Mass(\%) & Atom(\%) \\
\hline $\mathrm{C}$ & 33.45 & 30.53 & $\mathrm{C}$ & 25.46 & 23.99 \\
\hline $\mathrm{O}$ & 52.48 & 63.79 & $\mathrm{O}$ & 54.90 & 68.90 \\
\hline $\mathrm{P}$ & 5.08 & 2.39 & $\mathrm{P}$ & 4.91 & 2.39 \\
\hline $\mathrm{Ca}$ & 8.86 & 3.23 & $\mathrm{Ca}$ & 11.88 & 4.47 \\
\hline $\mathrm{Pb}$ & $/$ & $/$ & $\mathrm{Pb}$ & 2.74 & 0.20 \\
\hline
\end{tabular}


Table S4. BET of HAP-BC Before and After Pb(II) Adsorption

\begin{tabular}{|c|c|}
\hline HAP-BC & BET $\left(\mathrm{m}^{2} \mathrm{~g}^{-1}\right)$ \\
\hline Before adsorption $\mathrm{Pb}(\mathrm{II})$ & 89.52 \\
\hline After adsorption $\mathrm{Pb}(\mathrm{II})$ & 83.19 \\
\hline
\end{tabular}

Table S5. Effect of the pH on Hydroxylapatite (HAP) Ion Concentrations

\begin{tabular}{|c|c|c|c|c|c|c|}
\hline \multirow{2}{*}{$\mathrm{pH}$} & \multicolumn{2}{|l|}{$\begin{array}{l}\text { Calcium Concentration } \\
\left(\mathrm{mmol} \cdot \mathrm{L}^{-1}\right)\end{array}$} & \multicolumn{2}{l|}{$\begin{array}{l}\text { Phosphate Concentration } \\
\left(\mathrm{mmol} \cdot \mathrm{L}^{-1}\right)\end{array}$} & \multicolumn{2}{l|}{$\begin{array}{l}\text { Calcium to Phosphorus } \\
\text { Molar Ratio }\end{array}$} \\
\cline { 2 - 7 } & \multicolumn{2}{|c|}{$\mathrm{C}_{0(\mathrm{~Pb})}\left(\mathrm{mg} \cdot \mathrm{L}^{-1}\right)$} & \multicolumn{2}{c|}{$\mathrm{C}_{0(\mathrm{~Pb})}\left(\mathrm{mg} \cdot \mathrm{L}^{-1}\right)$} & \multicolumn{2}{c|}{$\mathrm{C}_{0(\mathrm{~Pb})}\left(\mathrm{mg} \cdot \mathrm{L}^{-1}\right)$} \\
\cline { 2 - 7 } & 100 & 400 & 100 & 400 & 100 & 400 \\
\hline 2.1 & 4.28 & 5.68 & 2.46 & 2.16 & 1.74 & 2.63 \\
\hline 3.1 & 1.012 & 2.596 & 0.309 & 0.225 & 3.27 & 11.51 \\
\hline 4.0 & 0.411 & 1.466 & 0.049 & 0.047 & 8.38 & 31.16 \\
\hline 5.1 & 0.267 & 0.832 & 0.033 & 0.028 & 8.13 & 29.33 \\
\hline 6.1 & 0.382 & 1.272 & 0.025 & 0.015 & 15.20 & 82.23 \\
\hline 6.8 & 0.317 & 1.036 & 0.011 & 0.013 & 28.94 & 80.36 \\
\hline 7.9 & 0.199 & 0.525 & 0.004 & 0.008 & 51.48 & 62.62 \\
\hline 9.3 & 0.105 & 0.244 & 0.003 & 0.005 & 40.74 & 47.30 \\
\hline
\end{tabular}

